\title{
THE BEHAVIOR OF BOUNDS AND OSCILLATIONS OF SEQUENCES OF FUNCTIONS UNDER REGULAR TRANSFORMATIONS*
}

\author{
BY \\ RALPH PALMER AGNEW
}

Introduction. Much has been written during the past thirty years on summability $\dagger$ of sequences of constants. The subject of summability of sequences of functions is largely unexplored. $\ddagger$

Very recently Gillespie and Hurwitz§ discovered that any bounded sequence of real continuous functions, defined over a closed compact set $A$, which converges to a continuous limit function is uniformly summable by a regular transformation totally equivalent to a regular transformation with a triangular matrix. This fact creates an interest in summability of sequences of functions. In 1925 Hurwitz $\mathbb{T}$ discussed the behavior of what we shall call ultimate bounds of sequences of real constants under real regular transformations, and more recently he\| has considered the behavior of oscillations of complex and of real sequences of constants under complex and real regular transformations with triangular matrices.

In this paper, regular transformations with triangular matrices, which have been conspicuous in the theory of summability, will be applied to sequences of functions. We will consider the behavior of ultimate bounds of real sequences under real transformations, and of continuous oscillation and convergence and uniform oscillation and convergence of complex and real sequences under complex and real transformations; ultimate bounds, oscillations, and convergence being considered (1) over a set as a whole, (2) at a single point of a set, and (3) at all points and limit points of a set.**

\footnotetext{
* Presented to the Society, April 18, 1930; received by the editors April 2, 1930.

$\dagger$ For a bibliography of the subject, see Smail, History and Synopsis of the Theory of Summable Infinite Processes, University of Oregon Press, 1925.

$\ddagger$ However, it is well known that the Cesaro and certain other transformations preserve uniform convergence of bounded sequences of functions.

$\S$ D. C. Gillespie and W. A. Hurwitz, these Transactions, vol. 32, pp. 527-543.

If W. A. Hurwitz, Proceedings of the London Mathematical Society, (2), vol. 26, pp. 231-48.

\| W. A. Hurwitz, American Journal of Mathematics.

** In a paper to appear in the American Journal of Mathematics, entitled The behavior of mean square oscillation and convergence under regular transformations, the writer further extends the application of regular transformations to sequences of functions.
} 
We recall that a transformation with a triangular matrix is a sequence-tosequence transformation of the form

$$
\sigma_{n}=a_{n 1} s_{1}+a_{n 2} s_{2}+\cdots+a_{n n} s_{n}
$$

where the $a_{n k}$ are constants, and that a transformation is said to be regular when it carries every convergent sequence $\left\{s_{n}\right\}$ into a sequence $\left\{\sigma_{n}\right\}$ which converges to the same value. Such a transformation is said to be real when $a_{n k}$ is real for all $n$ and $k$; otherwise it is complex. The following ten conditions to which we shall refer repeatedly in this paper are catalogued together for convenience:

$$
\begin{aligned}
& \mathrm{C}_{1}: \quad \sum_{k=1}^{n}\left|a_{n k}\right| \text { is bounded for all } n ; \\
& \mathrm{C}_{2}: \quad \text { for each } k, \lim _{n \rightarrow \infty} a_{n k}=0 ; \\
& \mathrm{C}_{3}: \quad \lim _{n \rightarrow \infty} \sum_{k=1}^{n} a_{n k}=1 ; \\
& \mathrm{C}_{4}: \quad \lim _{n \rightarrow \infty} \sum_{k=1}^{n}\left|a_{n k}\right|=1 ; \\
& \mathrm{C}_{5}: \quad \text { for each } k, a_{n k}=0 \text { for almost* all } n ; \\
& \mathrm{C}_{6}: \quad \sum_{k=1}^{n} a_{n k}=1 \text { for almost all } n ; \\
& \mathrm{C}_{7}: \quad a_{n k} \geqq 0 \text { for almost all } k ; \\
& \mathrm{C}_{8}: \quad \text { for each } k, a_{n k} \geqq 0 \text { for almost all } n ; \\
& \mathrm{C}_{9}: \quad \text { for each } k, a_{n k} \leqq 0 \text { for almost all } n ; \\
& \mathrm{C}_{10}: \quad a_{n k} \geqq 0 \text { for almost all } n .
\end{aligned}
$$

The reader will find it helpful to think of each of the ten conditions in terms of the triangular matrix of which the $n$th row is $a_{n 1}, a_{n 2}, \cdots, a_{n n}$, and the $k$ th column is $a_{k k}, a_{k+1, k}, a_{k+2, k}, \cdots$. Thus $\mathrm{C}_{6}$ indicates that there is a certain row such that the sum of the elements in any lower row is $1, \mathrm{C}_{7}$ indicates that all elements to the right of a certain fixed column are non-negative, $\mathrm{C}_{10}$ indicates that all elements below a certain fixed row are non-negative, etc.

Let the symbol $(T)$ represent a regular transformation with a triangular matrix. By the Silverman-Toeplitz theorem, in order that a complex (or real) transformation may be regular when applied to complex (or real) sequences, $\mathrm{C}_{1}, \mathrm{C}_{2}$, and $\mathrm{C}_{3}$ are necessary and sufficient. Hence $(T)$, complex

\footnotetext{
* I.e., $a_{n k}=0$ except for at most a finite number, depending on $k$, of values of $n$.
} 
or real, satisfies $\mathrm{C}_{1}, \mathrm{C}_{2}$, and $\mathrm{C}_{3}$. The conditions $\mathrm{C}_{4}$ and $\mathrm{C}_{7}$ were used by Hurwitz, ${ }^{*}$ and $\mathrm{C}_{5}, \mathrm{C}_{8}, \mathrm{C}_{8}, \mathrm{C}_{9}$, and $\mathrm{C}_{10}$ are used for the first time in this paper.

The functions $f(x)$ and $s(x)$ considered in this paper are regarded as being defined over a non-empty set $A$ of any abstract metric space; however any reader not interested in this degree of generality may regard the set $A$ as being in euclidean space $\dagger$ of one or more dimensions. In all sections where complex functions are considered, an interesting special case is obtained by regarding $A$ as being a set in a euclidean plane so that a point $x$ of $A$ determines two coördinates, say $\xi$ and $\eta$, and a complex function $f(x)$ may be written $u(\xi, \eta)+i v(\xi, \eta)$; if one cares to demand that $u$ and $v$ shall satisfy the Cauchy-Riemann differential equations, then $f(x)$ is an analytic function of the complex variables $(\xi+i \eta)$. Throughout this paper, $f(x)$ is finite for each value of $x$ for which it is defined, but the symbols $+\infty$ and $-\infty$ are admitted as limits and bounds.

The wordings of the theorems of the various sections of this paper have been made as similar as possible to make essential differences apparent and to facilitate the proofs. The reader may note that alternative statements of some of the theorems are desirable; for example, Theorem 7.12 is equivalent to the following:

Any regular transformation with a triangular matrix carries every sequence which is bounded and uniformly convergent over a given set into a sequence which converges uniformly over the set to the same limit function.

\section{Chapter I. Bounds of Real Sequences}

In this chapter, all sequences and transformations considered are real.

Two facts, established by W. A. Hurwitz $\ddagger$ to which we shall have occasion to refer in this chapter are stated in the following lemmas:

Lemma 1.01. In order that $(T)$ may be such that

$$
\limsup _{n \rightarrow \infty} \sigma_{n} \leqq \limsup _{n \rightarrow \infty} s_{n}
$$

for all sequences $\left\{s_{n}\right\}$ of constants for which the right member is finite, $\mathrm{C}_{7}$ is necessary and sufficient.

LEMma 1.02. If (T) fails to satisfy $\mathrm{C}_{4}$, then there is a bounded sequence $\left\{s_{n}\right\}$ of constants such that

$$
\limsup _{n \rightarrow \infty} \sigma_{n}>\limsup _{n \rightarrow \infty} s_{n} .
$$

\footnotetext{
* Proceedings of the London Mathematical Society, loc. cit.

$\dagger$ In any euclidean space, any bounded set is compact and conversely.

$\ddagger$ Proceedings of the London Mathematical Society, vol. 26 (1925), pp. 232-237.
} 


\section{Ultimate boundS OF SEQUenCES OVER A SET}

Let a sequence $\left\{f_{n}(x)\right\}$ be defined over a set $A$. Then $G\left(f_{n} ; A\right)$ is the least upper bound of the element $f_{n}(x)$ of the sequence over the set $A$; and lim $\sup _{n \rightarrow \infty} G\left(f_{n} ; A\right)$ may appropriately be called the ultimate least upper bound of the sequence $\left\{f_{n}(x)\right\}$ over the set $A$. Analogously $g\left(f_{n} ; A\right)$ is the greatest lower bound of $f_{n}(x)$ over $A$, and $\lim _{\inf _{n \rightarrow \infty}} g\left(f_{n} ; A\right)$ is the ultimate greatest lower bound of $\left\{f_{n}(x)\right\}$ over $A$.

The seven theorems $1.110-1.123$ give necessary and sufficient conditions that $(T)$ shall not increase ultimate least upper bounds of sequences over a set.

THEOREM 1.110. In order that $(T)$ may be such that

$$
\limsup _{n \rightarrow \infty} G\left(\sigma_{n} ; A\right) \leqq \limsup _{n \rightarrow \infty} G\left(s_{n} ; A\right)
$$

for every sequence $\left\{s_{n}(x)\right\}$, defined over an arbitrary set $A$ and bounded over $A$ for all $n, \mathrm{C}_{4}$ is necessary and sufficient.

The condition $\mathrm{C}_{4}$ is necessary, for it follows from Lemma 1.02 that it is necessary for (1.1101) when bounded sequences of constants are considered. The condition $\mathrm{C}_{4}$ is sufficient. Given an admissible sequence $\left\{s_{n}(x)\right\}$, choose $M$ so that $\left|s_{n}(x)\right|<M$ over $A$ for all $n$ and let $q$ be any number greater than $\lim \sup G\left(s_{n} ; A\right)$. Choose an index $p$ such that $G\left(s_{n} ; A\right)<q$ for $n>p$; then $s_{n}(x)<q$ over $A$ for $n>p$. Let $b_{n k}=\frac{1}{2}\left(\left|a_{n k}\right|+a_{n k}\right) \geqq 0$ and $c_{n k}=\frac{1}{2}\left(\left|a_{n k}\right|-a_{n k}\right)$ $\geqq 0$ so that $\left|a_{n k}\right|=b_{n k}+c_{n k}$ and $a_{n k}=b_{n k}-c_{n k}$. Then for $n>p$ and each $x$ in $A$

$$
\begin{aligned}
& \sigma_{n}(x)=\sum_{k=1}^{p} a_{n k} s_{k}-\sum_{k=p+1}^{n} c_{n k} s_{k}+\sum_{k=p+1}^{n} b_{n k} s_{k}, \\
& \sigma_{n}(x) \leqq M \sum_{k=1}^{p}\left|a_{n k}\right|+M \sum_{k=p+1}^{n} c_{n k}+q \sum_{k=p+1}^{n} b_{n k} .
\end{aligned}
$$

Since the right member of (1.1103) is independent of $x$, we have for $n>p$

$$
G\left(\sigma_{n} ; A\right) \leqq M \sum_{k=1}^{p}\left|a_{n k}\right|+M \sum_{k=p+1}^{n} c_{n k}+q \sum_{k=p+1}^{n} b_{n k} .
$$

Using $\mathrm{C}_{4}$ and the regularity of $(T)$ we obtain the following five relations the first three of which hold for each fixed $k$ :

$$
\lim _{n \rightarrow \infty}\left|a_{n k}\right|=0, \lim _{n \rightarrow \infty} c_{n k}=0, \lim _{n \rightarrow \infty} b_{n k}=0, \lim _{n \rightarrow \infty} \sum_{k=1}^{n} c_{n k}=0, \lim _{n \rightarrow \infty} \sum_{k=1}^{n} b_{n k}=1 ;
$$

and due to these relations it follows from (1.1104) that $\lim \sup G\left(\sigma_{n} ; A\right) \leqq q$. 
Since $q$ is any number greater than $\lim \sup G\left(s_{n} ; A\right)$, (1.1101) follows and $\mathrm{C}_{4}$ is sufficient.

Two theorems, the proofs of which may be made to depend on those of other theorems, are the following:

Theorem 1.111. In order that $(T)$ may be such that

$$
\limsup _{n \rightarrow \infty} G\left(\sigma_{n} ; A\right) \leqq \limsup _{n \rightarrow \infty} G\left(s_{n} ; A\right)
$$

for every sequence $\left\{s_{n}(x)\right\}$, defined over a finite set $A$ and bounded above over $A$ for all $n$, such that the right member is finite, $\mathrm{C}_{7}$ is necessary and sufficient.

TheOREM 1.112. In order that $(T)$ may be such that

$$
\limsup _{n \rightarrow \infty} G\left(\sigma_{n} ; A\right) \leqq \limsup _{n \rightarrow \infty} G\left(s_{n} ; A\right)
$$

for every sequence $\left\{s_{n}(x)\right\}$, defined over a finite set $A$ and bounded below over $A$ for all $n$, such that the right member is finite, $\mathrm{C}_{4}$ is necessary and sufficient.

Since $A$ is a finite set, the condition $s_{n}(x)$ is bounded above over $A$ for all $n$ is automatically satisfied by every sequence $\left\{s_{n}(x)\right\}$ for which $\lim \sup G\left(s_{n} ; A\right)$ is finite. Therefore Theorem 1.111 is equivalent to Theorem 1.113 and may be proved simultaneously with it; and Theorem 1.112 follows from Theorem 1.110 .

TheOREM 1.113. In order that $(T)$ may be such that

$$
\limsup _{n \rightarrow \infty} G\left(\sigma_{n} ; A\right) \leqq \limsup _{n \rightarrow \infty} G\left(s_{n} ; A\right)
$$

for every sequence $\left\{s_{n}(x)\right\}$, defined over a finite set $A$, such that the right member is finite, $\mathrm{C}_{7}$ is necessary and sufficient.

Necessity follows from Lemma 1.01. The condition is sufficient. Let $q$ be any number greater than $\lim \sup G\left(s_{n} ; A\right)$, and choose an index $p$ such that $G\left(s_{n} ; A\right)<q$ for $n>p$ and also $a_{n k} \geqq 0$ for $k>p$. Since $A$ is finite, $s_{n}(x)$ is bounded over $A$ for each $n$; hence there is a constant $M$ such that $\left|s_{n}(x)\right|<M$ over $A$ for $n=1,2,3, \cdots, p$. Therefore for $n>p$ and each $x$ in $A$

$$
\sigma_{n}(x)=\sum_{k=1}^{p} a_{n k} s_{k}+\sum_{k=p+1}^{n} a_{n k} s_{k} \leqq M \sum_{k=1}^{p}\left|a_{n k}\right|+q \sum_{k=p+1}^{n} a_{n k},
$$

and

$$
G\left(\sigma_{n} ; A\right) \leqq M \sum_{k=1}^{p}\left|a_{n k}\right|+q \sum_{k=p+1}^{n} a_{n k} .
$$

Since $(T)$ is regular, $\lim \sup G\left(\sigma_{n} ; A\right) \leqq q$, and sufficiency follows 
ThEOREM 1.121. In order that $(T)$ may be such that

$$
\limsup _{n \rightarrow \infty} G\left(\sigma_{n} ; A\right) \leqq \underset{n \rightarrow \infty}{\lim \sup } G\left(s_{n} ; A\right)
$$

for every sequence $\left\{s_{n}(x)\right\}$, defined over an infinite set $A$ and bounded above over $A$ for all $n$, such that the right member is finite, $\mathrm{C}_{10}$ is necessary and suffcient.

We shall show that $C_{10}$ is necessary by showing that $C_{7}$ and $C_{8}$, which taken together are equivalent to $C_{10}$, are both necessary. The necessity of $\mathrm{C}_{7}$ follows from Lemma 1.01. To show that $\mathrm{C}_{8}$ is necessary, we shall suppose that $(\tilde{T})$ fails to satisfy $\mathrm{C}_{8}$ and construct a sequence $\left\{s_{n}(x)\right\}$ satisfying the conditions of the theorem for which (1.1211) is denied. From a denial of $\mathrm{C}_{8}$ it follows that there is a value of $k$, say $\lambda$, and a sequence $\left\{n_{\alpha}\right\}$ of indices such that $\lim n_{\alpha}=+\infty$ and $a_{n_{\alpha} \lambda}<0$ for $\alpha=1,2,3, \ldots$. Let $\left\{x_{\alpha}\right\}$ be a sequence of distinct points of $A$, and define the sequence $\left\{s_{n}(x)\right\}$ over $A$ as follows: $s_{n}(x) \equiv 0, n \neq \lambda ; s_{\lambda}(x)=0, x \neq x_{1}, x_{2}, x_{3}, \cdots ;$ and $s_{\lambda}\left(x_{\alpha}\right)=1 / a_{n_{\alpha} \lambda}$, $\alpha=1,2,3, \cdots$. Note that $s_{n}(x)$ is bounded above (by 0 ) over $A$ for all $n$ and that $\lim \sup G\left(s_{n} ; A\right)=\lim \inf g\left(s_{n} ; A\right)=0$. $^{*}$ However for $n_{\alpha} \geqq \lambda$, $\sigma_{n_{\alpha}}\left(x_{\alpha}\right)=1, \alpha=1,2,3, \cdots$, so that $G\left(\sigma_{n_{\alpha}} ; A\right) \geqq 1, \alpha=1,2,3, \cdots$, and $\lim \sup G\left(\sigma_{n} ; A\right) \geqq 1$. Thus, for this sequence $\left\{s_{n}(x)\right\},(1.1211)$ is denied and the necessity follows. To establish sufficiency of $\mathrm{C}_{10}$, choose $M$ such that $s_{n}(x)<M$ over $A$ for all $n$ and define $q$ and $p$ as in the preceding theorems. Let $p$ be increased if necessary so that $a_{n k} \geqq 0$ for $n>p$. Then for $n>p$ and each $x$ in $A$

$$
\sigma_{n}(x)=\sum_{k=1}^{p} a_{n k} s_{k}+\sum_{k=p+1}^{n} a_{n k} s_{k} \leqq M \sum_{k=1}^{p} a_{n k}+q \sum_{k=p+1}^{n} a_{n k}
$$

and since $(T)$ is regular, $\lim \sup G\left(\sigma_{n} ; A\right) \leqq q$ and sufficiency follows.

TheOREM 1.122. In order that $(T)$ may be such that

$$
\limsup _{n \rightarrow \infty} G\left(\sigma_{n} ; A\right) \leqq \limsup _{n \rightarrow \infty} G\left(s_{n} ; A\right)
$$

for every sequence $\left\{s_{n}(x)\right\}$, defined over an infinite set $A$ and bounded below over $A$ for all $n$, such that the right member is finite, $\mathrm{C}_{4}$ and $\mathrm{C}_{9}$ are necessary and sufficient.

Necessity of $\mathrm{C}_{4}$ follows from Theorem 1.110. The necessity of $\mathrm{C}_{9}$ is established here, where $s_{n}(x)$ is not assumed bounded above, by using the method used in Theorem 1.121, where $s_{n}(x)$ was not assumed bounded below,

* The fact that $\lim \inf g\left(s_{n} ; A\right)$ isfinite will be used in the proof of Theorem 1.321. 
to prove that $\mathrm{C}_{8}$ was a necessary condition. To establish sufficiency, choose $\mu$ such that $s_{n}(x)>\mu$ over $A$ for all $n$ and define $q$ and $p$ as usual. Due to $\mathrm{C}_{\vartheta}$ there is an index $N \geqq p$ such that $a_{n k} \leqq 0$ for $k=1,2,3, \cdots, p$ when $n>N$. Hence for $n>N$ and $x$ in $A$

$$
\sigma_{n}(x) \leqq \mu \sum_{k=1}^{p} a_{n k}-\mu \sum_{k=p+1}^{n} c_{n k}+q \sum_{k=p+1}^{n} b_{n k}
$$

where $c_{n k}$ and $b_{n k}$ are the non-negative constants defined in Theorem 1.110. Using $\mathrm{C}_{4}$ and the regularity of $(T)$, we find that $\lim \sup G\left(\sigma_{n} ; A\right) \leqq q$ and sufficiency follows.

TheOREM 1.123. In order that $(T)$ may be such that

$$
\limsup _{n \rightarrow \infty} G\left(\sigma_{n} ; A\right) \leqq \limsup _{n \rightarrow \infty} G\left(s_{n} ; A\right)
$$

for every sequence $\left\{s_{n}(x)\right\}$, defined over an infinite set $A$, such that the right member is finite, $\mathrm{C}_{10}$ and $\mathrm{C}_{5}$ are necessary and sufficient.

That $\mathrm{C}_{10}$ and $\mathrm{C}_{9}$ are necessary follows from Theorems 1.121 and 1.122. But $\mathrm{C}_{10}$ and $\mathrm{C}_{9}$ are equivalent to $\mathrm{C}_{10}$ and $\mathrm{C}_{5}$; thus necessity is proved. To establish sufficiency, define $q$ and $p$ as usual and increase $p$ if necessary so that $a_{n k} \geqq 0$ for $n>p$. Due to $\mathrm{C}_{5}$ there is an index $N \geqq p$ such that $a_{n k}=0$, $k=1,2,3, \cdots, p$, for $n>N$. Then we have for $n>N$ and each $x$ in $A$

$$
\sigma_{n}(x)=\sum_{k=1}^{p} a_{n k} s_{k}+\sum_{k=p+1}^{n} a_{n k} s_{k}=\sum_{k=p+1}^{n} a_{n k} s_{k} \leqq q \sum_{k=p+1}^{n} a_{n k} ;
$$

hence $\lim \sup G\left(\sigma_{n} ; A\right) \leqq q$ and sufficiency follows.

The seven theorems 1.210-1.223 give necessary and sufficient conditions that $(T)$ shall not decrease ultimate greatest lower bounds of sequences over a set. Rewriting Theorems 1.110, 1.112, 1.111, 1.113, 1.122, 1.121, and 1.123 with $s_{n}(x)$ replaced by $-s_{n}(x)$ and hence $\sigma_{n}(x)$ replaced by $-\sigma_{n}(x)$, and taking into account facts such as $\lim \sup G\left(-f_{n} ; A\right)=-\lim \inf g\left(f_{n} ; A\right)$ and if $-s_{n}(x)$ is bounded above over $A$ for all $n$ then $s_{n}(x)$ is bounded below over $A$ for all $n$, we obtain respectively the seven theorems:

ThEOREM 1.210. In order that $(T)$ may be such that

$$
\underset{n \rightarrow \infty}{\lim \inf } g\left(\sigma_{n} ; A\right) \geqq \lim _{n \rightarrow \infty} \inf g\left(s_{n} ; A\right)
$$

for every sequence $\left\{s_{n}(x)\right\}$, defined over an arbitrary set $A$ and bounded over $A$ for all $n, \mathrm{C}_{4}$ is necessary and sufficient. 
TheORem 1.211. In order that $(T)$ may be such that

$$
\liminf _{n \rightarrow \infty} g\left(\sigma_{n} ; A\right) \geqq \liminf _{n \rightarrow \infty} g\left(s_{n} ; A\right)
$$

for every sequence $\left\{s_{n}(x)\right\}$, defined over a finite set $A$ and bounded above over $A$ for all $n$, such that the right member is finite, $\mathrm{C}_{4}$ is necessary and sufficient.

Theorem 1:212. In order that (T) may be such that

$$
\liminf _{n \rightarrow \infty} g\left(\sigma_{n} ; A\right) \geqq \liminf _{n \rightarrow \infty} g\left(s_{n} ; A\right)
$$

for every sequence $\left\{s_{n}(x)\right\}$, defined over a finite set $A$ and bounded below over $A$ for all $n$, such that the right member is finite, $\mathrm{C}_{7}$ is necessary and sufficient.

Theorem 1.213. In order that $(T)$ may be such that

$$
\liminf _{n \rightarrow \infty} g\left(\sigma_{n} ; A\right) \geqq \liminf _{n \rightarrow \infty} g\left(s_{n} ; A\right)
$$

for every sequence $\left\{s_{n}(x)\right\}$, defined over a finite set $A$, such that the right member is finite, $\mathrm{C}_{7}$ is necessary and sufficient.

THEOREM 1.221. In order that $(T)$ may be such that

$$
\liminf _{n \rightarrow \infty} g\left(\sigma_{n} ; A\right) \geqq \liminf _{n \rightarrow \infty} g\left(s_{n} ; A\right)
$$

for every sequence $\left\{s_{n}(x)\right\}$, defined over an infinite set $A$ and bounded above over $A$ for all $n$, such that the right member is finite, $\mathrm{C}_{4}$ and $\mathrm{C}_{9}$ are necessary and sufficient.

THEOREM 1.222. In order that $(T)$ may be such that

$$
\liminf _{n \rightarrow \infty} g\left(\sigma_{n} ; A\right) \geqq \liminf _{n \rightarrow \infty} g\left(s_{n} ; A\right)
$$

for every sequence $\left\{s_{n}(x)\right\}$, defined over an infinite set $A$ and bounded below over $A$ for all $n$, such that the right member is finite, $\mathrm{C}_{10}$ is necessary and suffcient.

Theorem 1.223. In order that $(T)$ may be such that

$$
\liminf _{n \rightarrow \infty} g\left(\sigma_{n} ; A\right) \geqq \liminf _{n \rightarrow \infty} g\left(s_{n} ; A\right)
$$

for every sequence $\left\{s_{n}(x)\right\}$, defined over an infinite set $A$, such that the right member is finite, $\mathrm{C}_{10}$ and $\mathrm{C}_{5}$ are necessary and sufficient.

The seven theorems 1.310-1.323 give necessary and sufficient conditions that a transformation shall neither increase ultimate least upper bounds nor decrease ultimate greatest lower bounds of sequences. 
We may combine Theorems 1.110 and 1.210 to obtain

THEOREM 1.310. In order that $(T)$ may be such that

$$
\limsup _{n \rightarrow \infty} G\left(\sigma_{n} ; A\right) \leqq \limsup _{n \rightarrow \infty} G\left(s_{n} ; A\right)
$$

and

$$
\liminf _{n \rightarrow \infty} g\left(\sigma_{n} ; A\right) \geqq \liminf _{n \rightarrow \infty} g\left(s_{n} ; A\right)
$$

for every sequence $\left\{s_{n}(x)\right\}$, defined over an arbitrary set $A$ and bounded over $A$ for all $n, \mathrm{C}_{4}$ is necessary and sufficient.

The three following theorems may be proved simultaneously.

Theorems 1.311, 1.312. In order that $(T)$ may be such that

and

$$
\limsup _{n \rightarrow \infty} G\left(\sigma_{n} ; A\right) \leqq \limsup _{n \rightarrow \infty} G\left(s_{n} ; A\right)
$$

$$
\liminf _{n \rightarrow \infty} g\left(\sigma_{n} ; A\right) \geqq \liminf _{n \rightarrow \infty} g\left(s_{n} ; A\right)
$$

for every sequence $\left\{s_{n}(x)\right\}$, defined over a finite set $A$ and bounded above (below) over $A$ for all $n$, such that the right members are finite, $\mathrm{C}_{4}$ is necessary and sufficient.

TheOREM 1.313. In order that $(T)$ may be such that

$$
\limsup _{n \rightarrow \infty} G\left(\sigma_{n} ; A\right) \leqq \limsup _{n \rightarrow \infty} G\left(s_{n} ; A\right)
$$

and

$$
\liminf _{n \rightarrow \infty} g\left(\sigma_{n} ; A\right) \geqq \liminf _{n \rightarrow \infty} g\left(s_{n} ; A\right)
$$

for every sequence $\left\{s_{n}(x)\right\}$, defined over a finite set $A$, such that the right members are finite, $\mathrm{C}_{4}$ is necessary and sufficient.

Since $A$ is a finite set, the sequences $\left\{s_{n}(x)\right\}$ considered in each of the three theorems are precisely the sequences $\left\{s_{n}(x)\right\}$ which are bounded over $A$ for all $n$; hence each of the three theorems follows from Theorem 1.310.

THEOREM 1.321. In order that $(T)$ may be such that

$$
\limsup _{n \rightarrow \infty} G\left(\sigma_{n} ; A\right) \leqq \limsup _{n \rightarrow \infty} G\left(s_{n} ; A\right)
$$

and

$$
\liminf _{n \rightarrow \infty} g\left(\sigma_{n} ; A\right) \liminf _{n \rightarrow \infty} g\left(s_{n} ; A\right)
$$

for every sequence $\left\{s_{n}(x)\right\}$, defined over an infinite set $A$ and bounded above over $A$ for all $n$, such that the right members are finite, $\mathrm{C}_{4}$ and $\mathrm{C}_{5}$ are necessary and sufficient. 
The necessity of $\mathrm{C}_{4}$ is contained in Theorem 1.310. That $\mathrm{C}_{8}$ is necessary for (1.3211) under the present conditions was established in the course of the proof of Theorem 1.121. The proof of Theorem 1.122 is easily made to show that $\mathrm{C}_{9}$ is necessary for (1.1221) even when $\lim \inf g\left(s_{n} ; A\right)$ is supposed finite, and we find on replacing $s_{n}(x)$ by $-s_{n}(x)$ that $\mathrm{C}_{9}$ is necessary for (1.3212) under the present conditions. Since $\mathrm{C}_{8}$ and $\mathrm{C}_{9}$ are necessary, $\mathrm{C}_{6}$ is necessary. To establish sufficiency, let $Q$ be any number greater than $\lim \sup G\left(s_{n} ; A\right)$ and $q$ be any number less than $\lim \inf g\left(s_{n} ; A\right)$. Choose an index $p$ such that $G\left(s_{n} ; A\right)<Q$ and $g\left(s_{n} ; A\right)>q$ for $n>p$. Using $\mathrm{C}_{5}$, choose an index $N \geqq p$ such that $a_{n k}=0, k=1,2,3, \cdots, p$, for $n>N$. Then, ưsing the notation of Theorem 1.110, we may write for $n>N$ and each $x$ in $A$

$$
\begin{aligned}
& -Q \sum_{k=p+1}^{n} c_{n k}+q \sum_{k=p+1}^{n} b_{n k} \leqq \sigma_{n}(x) \\
& \leqq-q \sum_{k=p+1}^{n} c_{n k}+Q \sum_{k=p+1}^{n} b_{n k} .
\end{aligned}
$$

Using $\mathrm{C}_{4}$ and the regularity of $(T)$ we find from the preceding relation that $q \leqq \lim \inf g\left(\sigma_{n} ; A\right)$ and lim sup $G\left(\sigma_{n} ; A\right) \leqq Q$; these relations imply (1.3211) and (1.3212) and sufficiency is proved.

Rewriting the preceding theorem with $s_{n}(x)$ replaced by $-s_{n}(x)$, we obtain

THEOREM 1.322. In order that $(T)$ may be such that

$$
\limsup _{n \rightarrow \infty} G\left(\sigma_{n} ; A\right) \leqq \limsup _{n \rightarrow \infty} G\left(s_{n} ; A\right)
$$

and

$$
\liminf _{n \rightarrow \infty} g\left(\sigma_{n} ; A\right) \geqq \liminf _{n \rightarrow \infty} g\left(s_{n} ; A\right)
$$

for every sequence $\left\{s_{n}(x)\right\}$, defined over an infinite set $A$ and bounded below over $A$ for all $n$, such that the right members are finite, $\mathrm{C}_{4}$ and $\mathrm{C}_{5}$ are necessary and sufficient.

THEOREM 1.323. In order that $(T)$ may be such that

and

$$
\limsup _{n \rightarrow \infty} G\left(\sigma_{n} ; A\right) \leqq \limsup _{n \rightarrow \infty} G\left(s_{n} ; A\right)
$$

$$
\liminf _{n \rightarrow \infty} g\left(\sigma_{n} ; A\right) \geqq \liminf _{n \rightarrow \infty} g\left(s_{n} ; A\right)
$$

for every sequence $\left\{s_{n}(x)\right\}$, defined over an infinite set $A$, such that the right members are finite, $\mathrm{C}_{4}$ and $\mathrm{C}_{5}$ are necessary and sufficient. 
Necessity is contained in Theorem 1.321 and sufficiency may be established verbatim as in Theorem 1.321.

\section{Ultimate boundS OF SEQUeNCES AT A POINT}

Let a sequence $\left\{f_{n}(x)\right\}$ be defined over a set $A$ and let $x_{0}$ be a point of $A^{0}$ where $A^{0}$ is the set consisting of the points and limit points of $A$. For each sequence $\left\{x_{i}\right\}$ of points of $A$ with the limit $x_{0}$, form

$$
\lim _{n \rightarrow \infty, i \rightarrow \infty} \sup _{n}\left(x_{i}\right)=v \text { and } \lim _{n \rightarrow \infty} \inf _{i \rightarrow \infty} f_{n}\left(x_{i}\right)=w \text {; }
$$

the least upper bound of all such $v$ is denoted by $\Gamma\left(x_{0} ;\left\{f_{n}\right\}, A\right)^{*}$ and may be called the ultimate least upper bound of the sequence $\left\{f_{n}(x)\right\}$ at the point $x_{0}$; the greatest lower bound of all such $w$ is denoted by $\gamma\left(x_{0} ;\left\{f_{n}\right\}, A\right)$ and may be called the ultimate greatest lower bound of the sequence $\left\{f_{n}(x)\right\}$ at the point $x_{n}$.

The seven theorems 2.110-2.123 give necessary and sufficient conditions that $(T)$ shall not increase ultimate least upper bounds of sequences at a point.

THEOREM 2.110. In order that $(T)$ may be such that

$$
\Gamma\left(x_{0} ;\left\{\sigma_{n}\right\}, A\right) \leqq \Gamma\left(x_{0} ;\left\{s_{n}\right\}, A\right)
$$

for every sequence $\left\{s_{n}(x)\right\}$, defined over an arbitrary set $A$ such that $x_{0}$ is in $A^{0}$ and bounded over a neighborhood $D$ of $x_{0}$ in $A$ for all $n, \mathrm{C}_{4}$ is necessary and sufficient.

Necessity is established as in Theorem 1.110. To prove sufficiency, choose $M$ so that $\left|s_{n}(x)\right|<M$ over $D$ for all $n$, let $q$ be any number greater than $\Gamma\left(x_{0} ;\left\{s_{n}\right\}, A\right)$, and let $\left\{x_{i}\right\}$ be any sequence of points of $A$ with the limit $x_{0}$. Choose an index $p$ such that $s_{n}\left(x_{i}\right)<q$ for $i>p, n>p$ and such that $x_{i}$ is in $D$ for $i>p$. Then we may write, for $x=x_{i}, n>p, i>p$, the relations (1.1102) and (1.1103). Using $C_{4}$ and the regularity of $(T)$ we find that

$$
\lim _{n \rightarrow \infty} \sup _{i \rightarrow \infty} \sigma_{n}\left(x_{i}\right) \leqq q ;
$$

hence $\Gamma\left(x_{0} ;\left\{\sigma_{n}\right\}, A\right) \leqq q,(2.1101)$ follows, and the theorem is proved.

THEOREM 2.111. In order that $(T)$ may be such that

$$
\Gamma\left(x_{0} ;\left\{\sigma_{n}\right\}, A\right) \leqq \Gamma\left(x_{0} ;\left\{s_{n}\right\}, A\right)
$$

for every sequence $\left\{s_{n}(x)\right\}$, defined over a set $A$ of which $x_{0}$ is an isolated point and bounded above over a neighborhood $D$ of $x_{0}$ in $A$ for all $n$, such that the right member is finite, $\mathrm{C}_{7}$ is necessary and sufficient.

* Hahn, Theorie der reellen Funktionen, p. 232. 
TheOREM 2.112. In order that (T) may be such that

$$
\Gamma\left(x_{0} ;\left\{\sigma_{n}\right\}, A\right) \leqq \Gamma\left(x_{0} ;\left\{s_{n}\right\}, A\right)
$$

for every sequence $\left\{s_{n}(x)\right\}$, defined over a set $A$ of which $x_{0}$ is an isolated point and bounded below over a neighborhood $D$ of $x_{0}$ in $A$ for all $n$, such that the right member is finite, $\mathrm{C}_{4}$ is necessary and sufficient.

Since $x_{0}$ is an isolated point of $A$, the condition $s_{n}(x)$ is bounded above over a neighborhood $D$ of $x_{0}$ in $A$ for all $n$ is automatically satisfied by every sequence $\left\{s_{n}(x)\right\}$ for which $\Gamma\left(x_{0} ;\left\{s_{n}\right\}, A\right)$ is finite. Therefore Theorem 2.111 is equivalent to Theorem 2.113 and may be proved simultaneously with it; and Theorem 2.112 follows from Theorem 2.110.

THEOREM 2.113. In order that $(T)$ may be such that

$$
\Gamma\left(x_{0} ;\left\{\sigma_{n}\right\}, A\right) \leqq \Gamma\left(x_{0} ;\left\{s_{n}\right\}, A\right)
$$

for every sequence $\left\{s_{n}(x)\right\}$, defined over a set $A$ of which $x_{0}$ is an isolated point, such that the right member is finite, $\mathrm{C}_{7}$ is necessary and sufficient.

If $\left\{x_{i}\right\}$ and $\left\{x_{i}{ }^{\prime}\right\}$ are any two sequences of points of $A$ with the limit $x_{0}$, then there is an index $p$ such that $x_{i}$ and $x_{i}{ }^{\prime}$ are $x_{0}$ for $i>p$. Hence

$$
\lim _{n \rightarrow \infty} \sup _{i \rightarrow \infty} \sigma_{n}\left(x_{i}\right)=\limsup _{n \rightarrow \infty} \sigma_{n}\left(x_{0}\right),
$$

and

$$
\limsup _{n \rightarrow \infty, i \rightarrow \infty} s_{n}\left(x_{i}^{\prime}\right)=\limsup _{n \rightarrow \infty} s_{n}\left(x_{0}\right)
$$

and (2.1131) is equivalent to the condition

$$
\limsup _{n \rightarrow \infty} \sigma_{n}\left(x_{0}\right) \leqq \limsup _{n \rightarrow \infty} s_{n}\left(x_{0}\right) \text {. }
$$

But $\left\{s_{n}\left(x_{0}\right)\right\}$ is a sequence of constants; thus the necessity and sufficiency of $\mathrm{C}_{7}$ follows from Lemma 1.01.

THEOREM 2.121. In order that $(T)$ may be such that

$$
\Gamma\left(x_{0} ;\left\{\sigma_{n}\right\}, A\right) \leqq \Gamma\left(x_{0} ;\left\{s_{n}\right\}, A\right)
$$

for every sequence $\left\{s_{n}(x)\right\}$, defined over a set $A$ of which $x_{0}$ is a limit point and bounded above over a neighborhood $D$ of $x_{0}$ in $A$ for all $n$, such that the right member is finite, $\mathrm{C}_{10}$ is necessary and sufficient.

The necessity proof is an adaptation of that of Theorem 1.121, the essential change being that the sequence $\left\{x_{\alpha}\right\}$ is for the present purpose taken to be a sequence of distinct points of $A$ with the limit $x_{0}$. The suff- 
ciency proof is a modification of that of Theorem 1.121 precisely as the sufficiency proof of Theorem 2.110 is a modification of that of Theorem 1.110

Similar proofs furnish the two following theorems:

ThEOREM 2.122. In order that $(T)$ may be such that

$$
\Gamma\left(x_{0} ;\left\{\sigma_{n}\right\}, A\right) \leqq \Gamma\left(x_{0} ;\left\{s_{n}\right\}, A\right)
$$

for every sequence $\left\{s_{n}(x)\right\}$, defined over a set $A$ of which $x_{0}$ is a limit point and bounded below over a neighborhood $D$ of $x_{0}$ in $A$ for all $n$, such that the right member is finite, $\mathrm{C}_{4}$ and $\mathrm{C}_{9}$ are necessary and sufficient.

ThEOREM 2.123. In order that $(T)$ may be such that

$$
\Gamma\left(x_{0} ;\left\{\sigma_{n}\right\}, A\right) \leqq \Gamma\left(x_{0} ;\left\{s_{n}\right\}, A\right)
$$

for every sequence $\left\{s_{n}(x)\right\}$, defined over a set $A$ of which $x_{0}$ is a limit point, such that the right member is finite, $\mathrm{C}_{10}$ and $\mathrm{C}_{5}$ are necessary and sufficient.

The seven theorems 2.210-2.223 give necessary and sufficient conditions that $(T)$ shall not decrease ultimate greatest lower bounds of sequences at a point. Rewriting Theorems 2.110, 2.112, 2.111, 2.113, 2.122, 2.121, and 2.123 with $s_{n}(x)$ replaced by $-s_{n}(x)$, and taking into account facts such as $\Gamma\left(x_{0} ;\left\{-f_{n}\right\}, A\right)=-\gamma\left(x_{0} ;\left\{f_{n}\right\}, A\right)$ we obtain respectively the seven theorems:

THEOREM 2.210. In order that $(T)$ may be such that

$$
\gamma\left(x_{0} ;\left\{\sigma_{n}\right\}, A\right) \geqq \gamma\left(x_{0} ;\left\{s_{n}\right\}, A\right)
$$

for every sequence $\left\{s_{n}(x)\right\}$, defined over a set $A$ such that $x_{0}$ is in $A^{0}$ and bounded over a neighborhood $D$ of $x_{0}$ in $A$ for all $n, C_{4}$ is necessary and sufficient.

THEOREM 2.211. In order that $(T)$ may be such that

$$
\gamma\left(x_{0} ;\left\{\sigma_{n}\right\}, A\right) \geqq \gamma\left(x_{0} ;\left\{s_{n}\right\}, A\right)
$$

for every sequence $\left\{s_{n}(x)\right\}$, defined over a set $A$ of which $x_{0}$ is an isolated point and bounded above over a neighborhood $D$ of $x_{0}$ in $A$ for all $n$, such that the right member is finite, $\mathrm{C}_{4}$ is necessary and sufficient.

THEOREM 2.212. In order that $(T)$ may be such that

$$
\gamma\left(x_{0} ;\left\{\sigma_{n}\right\}, A\right) \geqq \gamma\left(x_{0} ;\left\{s_{n}\right\}, A\right)
$$

for every sequence $\left\{s_{n}(x)\right\}$, defined over a set $A$ of which $x_{0}$ is an isolated point and bounded below over a neighborhood $D$ of $x_{0}$ in $A$ for all $n$, such that the right member is finite, $\mathrm{C}_{7}$ is necessary and sufficient. 
TheOREM 2.213. In order that $(T)$ may be such that

$$
\gamma\left(x_{0} ;\left\{\sigma_{n}\right\}, A\right) \geqq \gamma\left(x_{0} ;\left\{s_{n}\right\}, A\right)
$$

for every sequence $\left\{s_{n}(x)\right\}$, defined over a set $A$ of which $x_{0}$ is an isolated point, such that the right member is finite, $\mathrm{C}_{7}$ is necessary and sufficient.

THEOREM 2.221. In order that $(T)$ may be such that

$$
\gamma\left(x_{0} ;\left\{\sigma_{n}\right\}, A\right) \geqq \gamma\left(x_{0} ;\left\{s_{n}\right\}, A\right)
$$

for every sequence $\left\{s_{n}(x)\right\}$, defined over a set $A$ of which $x_{0}$ is a limit point and bounded above over a neighborhood $D$ of $x_{0}$ in $A$ for all $n$, such that the right member is finite, $\mathrm{C}_{4}$ and $\mathrm{C}_{9}$ are necessary and sufficient.

ThEOREM 2.222. In order that $(T)$ may be such that

$$
\gamma\left(x_{0} ;\left\{\sigma_{n}\right\}, A\right) \geqq \gamma\left(x_{0} ;\left\{s_{n}\right\}, A\right)
$$

for every sequence $\left\{s_{n}(x)\right\}$, defined over a set $A$ of which $x_{0}$ is a limit point and bounded below over a neighborhood $D$ of $x_{0}$ in $A$ for all $n$, such that the right member is finite, $\mathrm{C}_{10}$ is necessary and sufficient.

ThEOREM 2.223. In order that $(T)$ may be such that

$$
\gamma\left(x_{0} ;\left\{\sigma_{n}\right\}, A\right) \geqq \gamma\left(x_{0} ;\left\{s_{n}\right\}, A\right)
$$

for every sequence $\left\{s_{n}(x)\right\}$, defined over a set $A$ of which $x_{0}$ is a limit point, such that the right member is finite, $\mathrm{C}_{10}$ and $\mathrm{C}_{5}$ are necessary and sufficient.

The seven theorems 2.310-2.323 give necessary and sufficient conditions that $(T)$ shall neither increase ultimate least upper bounds nor decrease ultimate greatest lower bounds of sequences at a point. The proofs of these theorems are modifications of the proofs of the corresponding theorems of $\$ 1$.

THEOREM 2.310. In order that $(T)$ may be such that

$$
\Gamma\left(x_{0} ;\left\{\sigma_{n}\right\}, A\right) \leqq \Gamma\left(x_{0} ;\left\{s_{n}\right\}, A\right)
$$

and

$$
\gamma\left(x_{0} ;\left\{\sigma_{n}\right\}, A\right) \geqq \gamma\left(x_{0} ;\left\{s_{n}\right\}, A\right)
$$

for every sequence $\left\{s_{n}(x)\right\}$, defined over a set $A$ such that $x_{0}$ is in $A^{0}$ and bounded over a neighborhood $D$ of $x_{0}$ in $A$ for all $n, \mathrm{C}_{4}$ is necessary and sufficient. 
Theorems $2.311,2.312$. In order that $(T)$ may be such that

$$
\Gamma\left(x_{0} ;\left\{\sigma_{n}\right\}, A\right) \leqq \Gamma\left(x_{0} ;\left\{s_{n}\right\}, A\right)
$$

and

$$
\gamma\left(x_{0} ;\left\{\sigma_{n}\right\}, A\right) \geqq \gamma\left(x_{0} ;\left\{s_{n}\right\}, A\right)
$$

for every sequence $\left\{s_{n}(x)\right\}$, defined over a set $A$ of which $x_{0}$ is an isolated point and bounded above (below) over a neighborhood $D$ of $x_{0}$ in $A$ for all $n$, such that the right members are finite, $\mathrm{C}_{4}$ is necessary and sufficient.

THEOREM 2.313. In order that $(T)$ may be such that

$$
\Gamma\left(x_{0} ;\left\{\sigma_{n}\right\}, A\right) \leqq \Gamma\left(x_{0} ;\left\{s_{n}\right\}, A\right)
$$

and

$$
\gamma\left(x_{0} ;\left\{\sigma_{n}\right\}, A\right) \geqq \gamma\left(x_{0} ;\left\{s_{n}\right\}, A\right)
$$

for every sequence $\left\{s_{n}(x)\right\}$, defined over a set $A$ of which $x_{0}$ is an isolated point, such that the right members are finite, $\mathrm{C}_{4}$ is necessary and sufficient.

Theorems 2.321, 2.322. In order that $(T)$ may be such that

$$
\Gamma\left(x_{0} ;\left\{\sigma_{n}\right\}, A\right) \leqq \Gamma\left(x_{0} ;\left\{s_{n}\right\}, A\right)
$$

and

$$
\gamma\left(x_{0} ;\left\{\sigma_{n}\right\}, A\right) \geqq \gamma\left(x_{0} ;\left\{s_{n}\right\}, A\right)
$$

for every sequence $\left\{s_{n}(x)\right\}$, defined over a set $A$ of which $x_{0}$ is a limit point and bounded above (below) over a neighborhood $D$ of $x_{0}$ in $A$ for all $n$, such that the right members are finite, $\mathrm{C}_{4}$ and $\mathrm{C}_{5}$ are necessary and sufficient.

THEOREM 2.323. In order that $(T)$ may be such that

$$
\Gamma\left(x_{0} ;\left\{\sigma_{n}\right\}, A\right) \leqq \Gamma\left(x_{0} ;\left\{s_{n}\right\}, A\right)
$$

and

$$
\gamma\left(x_{0} ;\left\{\sigma_{n}\right\}, A\right) \geqq \gamma\left(x_{0} ;\left\{s_{n}\right\}, A\right)
$$

for every sequence $\left\{s_{n}(x)\right\}$, defined over a set $A$ of which $x_{0}$ is a limit point, such that the right members are finite, $\mathrm{C}_{4}$ and $\mathrm{C}_{5}$ are necessary and sufficient.

3. Ultimate bounds at ALL POINTS AND LIMIT POINTS OF A SET

In comparing the theorems of this section with those of $\$ 1$, the following facts, given as lemmas, should be noted. 
LEMMA 3.01. If

$$
\limsup _{n \rightarrow \infty} G\left(f_{n} ; A\right) \leqq \limsup _{n \rightarrow \infty} G\left(F_{n} ; A\right)
$$

where $A$ contains more than one point, then it is not necessarily true that $\Gamma\left(x ;\left\{f_{n}\right\}, A\right) \leqq \Gamma\left(x ;\left\{F_{n}\right\}, A\right)$ over $A$.

This lemma is established by considering the following simple sequences: $f_{n}\left(x_{1}\right)=1$, and $f_{n}(x)=0$ for $x \neq x_{1} ; F_{n}\left(x_{2}\right)=1$, and $F_{n}(x)=0$ for $x \neq x_{2}$; where $x_{1}$ and $x_{2}$ are two points of $A$. The first statement holds but the second fails for $x=x_{1}$. A change of the signs of the elements of the sequences establishes a corresponding lemma for ultimate greatest lower bounds.

Lemma 3.02. If $\Gamma\left(x ;\left\{f_{n}\right\}, A\right) \leqq \Gamma\left(x ;\left\{F_{n}\right\}, A\right)$ over $A^{0}$ and $A$ is compact, ${ }^{*}$ then

$$
\limsup _{n \rightarrow \infty} G\left(f_{n} ; A\right) \leqq \limsup _{n \rightarrow \infty} G\left(F_{n} ; A\right) .
$$

Suppose $A$ is compact and $\lim \sup G\left(f_{n} ; A\right)>\lim \sup G\left(F_{n} ; A\right)$; we shall show that the hypothesis is contradicted. Choose a number $\theta$ such that $\lim \sup G\left(f_{n} ; A\right)>\theta>\lim \sup G\left(F_{n} ; A\right)$. Then there is a sequence $\left\{n_{\alpha}\right\}$ such that $G\left(f_{n_{\alpha}}, A\right)>\theta$ for $\alpha=1,2,3, \cdots$, and hence a sequence $\left\{x_{\alpha}\right\}$ of points of $A$ such that $f_{n_{\alpha}}\left(x_{\alpha}\right)>\theta$. Since $A$ is compact, let $\left\{x_{\alpha}^{\prime}\right\}$ be a subsequence of $\left\{x_{\alpha}\right\}$ with a limit, say $x_{0}$; then $\Gamma\left(x_{0} ;\left\{f_{n}\right\}, A\right) \geqq \theta$. It is easy to show that lim sup $G\left(F_{n} ; A\right) \geqq \Gamma\left(x ;\left\{F_{n}\right\}, A\right)$ over $A^{0}$. Combining inequalities, we have $\Gamma\left(x_{0} ;\left\{f_{n}\right\}, A\right)>\Gamma\left(x ;\left\{F_{n}\right\}, A\right)$ over $A^{0}$, the hypothesis is denied, and the lemma is proved. A corresponding lemma for greatest lower bounds follows.

The seven theorems 3.110-3.123 give necessary and sufficient conditions that $(T)$ shall not increase ultimate least upper bounds of sequences at the points and limit points of a set.

From Theorems 2.110, 2.111, 2.112 and 2.113, we obtain respectively the following four theorems.

THEOREM 3.110. In order that $(T)$ may be such that

$$
\Gamma\left(x ;\left\{\sigma_{n}\right\}, A\right) \leqq \Gamma\left(x ;\left\{s_{n}\right\}, A\right) \text { over } A^{0}
$$

for every sequence $\left\{s_{n}(x)\right\}$, defined over an arbitrary set $A$ and bounded over $A$ for all $n, \mathrm{C}_{4}$ is necessary and sufficient.

* The condition " $A$ is compact" cannot be removed. To show this, let $\left\{x_{n}\right\}$ be a sequence of points of $A$ without limit points and define: $f_{n}\left(x_{n}\right)=2, f_{n}(x)=0$ for $x \neq x_{n}$; and $F_{n}(x)=1$ over $A$. Then $\Gamma(x$; $\left.\left\{f_{n}\right\}, A\right)=0$ over $A^{0}, \Gamma\left(x ;\left\{F_{n}\right\}, A\right)=1$ over $A^{0}, \lim \sup G\left(f_{n} ; A\right)=2$, and $\lim \sup G\left(F_{n} ; A\right)=1$ and the memla fails. 
ThEOREM 3.111. In order that $(T)$ may be such that

$$
\Gamma\left(x ;\left\{\sigma_{n}\right\}, A\right) \leqq \Gamma\left(x ;\left\{s_{n}\right\}, A\right) \text { over } A
$$

for every sequence $\left\{s_{n}(x)\right\}$, defined over a set $A$ without limit points and bounded above over $A$ for all $n$, such that the right member is finite for each $x$ in $A,{ }^{*}$ $\mathrm{C}_{7}$ is necessary and sufficient.

TheOREM 3.112. In order that $(T)$ may be such that

$$
\Gamma\left(x ;\left\{\sigma_{n}\right\}, A\right) \leqq \Gamma\left(x ;\left\{s_{n}\right\}, A\right) \text { over } A
$$

for every sequence $\left\{s_{n}(x)\right\}$, defined over a set $A$ without limit points and bounded below over $A$ for all $n$, such that the right member is finite for each $x$ in $A, \mathrm{C}_{4}$ is necessary and sufficient.

THEOREM 3.113. In order that $(T)$ may be such that

$$
\Gamma\left(x ;\left\{\sigma_{n}\right\}, A\right) \leqq \Gamma\left(x ;\left\{s_{n}\right\}, A\right) \text { over } A
$$

for every sequence $\left\{s_{n}(x)\right\}$, defined over a set $A$ without limit points, such that the right member is finite for each $x$ in $A, \mathrm{C}_{7}$ is necessary and sufficient.

Noting that any set is made up of limit points and isolated points, we obtain the necessity of the condition of the following theorem from Theorem 2.121 and the sufficiency from Theorems 2.121 and 2.111.

THEOREM 3.121. In order that $(T)$ may be such that

$$
\Gamma\left(x ;\left\{\sigma_{n}\right\}, A\right) \leqq \Gamma\left(x ;\left\{s_{n}\right\}, A\right) \text { over } A^{0}
$$

for every sequence $\left\{s_{n}(x)\right\}$, defined over a set $A$ with at least one limit point and bounded above over $A$ for all $n$, such that the right member is finite for each $x$ in $A^{0}, \mathrm{C}_{10}$ is necessary and sufficient.

Similarly we obtain from Theorems 2.122 and 2.112, and from Theorems 2.123 and 2.113 , the two following theorems:

THEOREM 3.122. In order that $(T)$ may be such that

$$
\Gamma\left(x ;\left\{\sigma_{n}\right\}, A\right) \leqq \Gamma\left(x ;\left\{s_{n}\right\}, A\right) \text { over } A^{0}
$$

for every sequence $\left\{s_{n}(x)\right\}$, defined over a set $A$ with at least one limit point and bounded below over $A$ for all $n$, such that the right member is finite for each $x$ in $A^{0}, \mathrm{C}_{4}$ and $\mathrm{C}_{9}$ are necessary and sufficient.

\footnotetext{
* But not necessarily bounded over $A$.
} 
TheOREM 3.123. In order that $(T)$ may be such that

$$
\Gamma\left(x ;\left\{\sigma_{n}\right\}, A\right) \leqq \Gamma\left(x ;\left\{s_{n}\right\}, A\right) \text { over } A^{0}
$$

for every sequence $\left\{s_{n}(x)\right\}$, defined over a set $A$ with at least one limit point, such that the right member is finite for each $x$ in $A^{0}, \mathrm{C}_{10}$ and $\mathrm{C}_{5}$ are necessary and sufficient.

The seven theorems 3.210-3.223, obtained from the preceding by replacing $s_{n}(x)$ by $-s_{n}(x)$, give necessary and sufficient conditions that $(T)$ shall not decrease ultimate greatest lower bounds of sequences at the points and limit points of a set.

THEOREM 3.210. In order that $(T)$ may be such that

$$
\gamma\left(x ;\left\{\sigma_{n}\right\}, A\right) \geqq \gamma\left(x ;\left\{s_{n}\right\}, A\right) \text { over } A^{0}
$$

for every sequence $\left\{s_{n}(x)\right\}$, defined over an arbitrary set $A$ and bounded over $A$ for all $n, \mathrm{C}_{4}$ is necessary and sufficient.

THEOREM 3.211. In order that $(T)$ may be such that

$$
\gamma\left(x ;\left\{\sigma_{n}\right\}, A\right) \geqq \gamma\left(x ;\left\{s_{n}\right\}, A\right) \text { over } A
$$

for every sequence $\left\{s_{n}(x)\right\}$, defined over a set $A$ without limit points and bounded above over $A$ for all $n$, such that the right member is finite for each $x$ in $A, \mathrm{C}_{4}$ is necessary and sufficient.

THEOREM 3.212. In order that $(T)$ may be such that

$$
\gamma\left(x ;\left\{\sigma_{n}\right\}, A\right) \geqq \gamma\left(x ;\left\{s_{n}\right\}, A\right) \text { over } A
$$

for every sequence $\left\{s_{n}(x)\right\}$, defined over a set $A$ without limit points and bounded below over $A$ for all $n$, such that the right member is finite for each $x$ in $A, \mathrm{C}_{7}$ is necessary and sufficient.

THEOREM 3.213. In order that $(T)$ may be such that

$$
\gamma\left(x ;\left\{\sigma_{n}\right\}, A\right) \geqq \gamma\left(x ;\left\{s_{n}\right\}, A\right) \text { over } A
$$

for every sequence $\left\{s_{n}(x)\right\}$, defined over a set $A$ without limit points, such that the right member is finite for each $x$ in $A, \mathrm{C}_{7}$ is necessary and sufficient.

THEOREM 3.221. In order that $(T)$ may be such that

$$
\gamma\left(x ;\left\{\sigma_{n}\right\}, A\right) \geqq \gamma\left(x ;\left\{s_{n}\right\}, A\right) \text { over } A^{0}
$$

for every sequence $\left\{s_{n}(x)\right\}$, defined over a set $A$ with at least one limit point and bounded above over $A$ for all $n$, such that the right member is finite for each $x$ in $A^{0}, \mathrm{C}_{4}$ and $\mathrm{C}_{9}$ are necessary and sufficient. 
ThEOREM 3.222. In order that $(T)$ may be such that

$$
\gamma\left(x ;\left\{\sigma_{n}\right\}, A\right) \geqq \gamma\left(x ;\left\{s_{n}\right\}, A\right) \text { over } A^{0}
$$

for every sequence $\left\{s_{n}(x)\right\}$, defined over a set $A$ with at least one limit point and bounded below over $A$ for all $n$, such that the right member is finite for each $x$ in $A^{0}, \mathrm{C}_{10}$ is necessary and sufficient.

THEOREM 3.223. In order that $(T)$ may be such that

$$
\gamma\left(x ;\left\{\sigma_{n}\right\}, A\right) \geqq \gamma\left(x ;\left\{s_{n}\right\}, A\right) \text { over } A^{0}
$$

for every sequence $\left\{s_{n}(x)\right\}$, defined over a set $A$ with at least one limit point, such that the right member is finite for each $x$ in $A^{0}, \mathrm{C}_{10}$ and $\mathrm{C}_{5}$ are necessary and sufficient.

The seven theorems 3.310-3.323, obtained from the last seven theorems of $\$ 2$, give necessary and sufficient conditions that $(T)$ shall neither increase ultimate least upper bounds nor decrease ultimate greatest lower bounds of sequences at the points and limit points of a set.

THEOREM 3.310. In order that $(T)$ may be such that

$$
\Gamma\left(x ;\left\{\sigma_{n}\right\}, A\right) \leqq \Gamma\left(x ;\left\{s_{n}\right\}, A\right) \text { over } A^{0}
$$

and

$$
\gamma\left(x ;\left\{\sigma_{n}\right\}, A\right) \geqq \gamma\left(x ;\left\{s_{n}\right\}, A\right) \text { over } A^{0}
$$

for every sequence $\left\{s_{n}(x)\right\}$, defined over an arbitrary set $A$ and bounded over $A$ for all $n, \mathrm{C}_{4}$ is necessary and sufficient.

Theorems 3.311, 3.312. In order that $(T)$ may be such that

$$
\Gamma\left(x ;\left\{\sigma_{n}\right\}, A\right) \leqq \Gamma\left(x ;\left\{s_{n}\right\}, A\right) \text { over } A
$$

and

$$
\gamma\left(x ;\left\{\sigma_{n}\right\}, A\right) \geqq \gamma\left(x ;\left\{s_{n}\right\}, A\right) \text { over } A
$$

for every sequence $\left\{s_{n}(x)\right\}$, defined over a set $A$ without limit points and bounded above (below) over $A$ for all $n$, such that the right members are finite for each $x$ in $A, \mathrm{C}_{4}$ is necessary and sufficient.

TheOREM 3.313. In order that $(T)$ may be such that

$$
\Gamma\left(x ;\left\{\sigma_{n}\right\}, A\right) \leqq \Gamma\left(x ;\left\{s_{n}\right\}, A\right) \text { over } A
$$

and

$$
\gamma\left(x ;\left\{\sigma_{n}\right\}, A\right) \geqq \gamma\left(x ;\left\{s_{n}\right\}, A\right) \text { over } A
$$

for every sequence $\left\{s_{n}(x)\right\}$, defined over a set $A$ without limit points, such that the right members are finite for each $x$ in $A, \mathrm{C}_{4}$ is necessary and sufficient. 
Theorems 3.321, 3.322. In order that $(T)$ may be such that

and

$$
\Gamma\left(x ;\left\{\sigma_{n}\right\}, A\right) \leqq \Gamma\left(x ;\left\{s_{n}\right\}, A\right) \text { over } A^{0}
$$

$$
\gamma\left(x ;\left\{\sigma_{n}\right\}, A\right) \geqq \gamma\left(x ;\left\{s_{n}\right\}, A\right) \text { over } A^{0}
$$

for every sequence $\left\{s_{n}(x)\right\}$, defined over a set $A$ with at least one limit point and bounded above (below) over $A$ for all $n$, such that the right members are finite for each $x$ in $A^{0}, \mathrm{C}_{4}$ and $\mathrm{C}_{5}$ are necessary and sufficient.

THEOREM 3.323. In order that $(T)$ may be such that

and

$$
\Gamma\left(x ;\left\{\sigma_{n}\right\}, A\right) \leqq \Gamma\left(x ;\left\{s_{n}\right\}, A\right) \text { over } A^{0}
$$

$$
\gamma\left(x ;\left\{\sigma_{n}\right\}, A\right) \geqq \gamma\left(x ;\left\{s_{n}\right\}, A\right) \text { over } A^{0}
$$

for every sequence $\left\{s_{n}(x)\right\}$, defined over a set $A$ with at least one limit point, such that the right members are finite for each $x$ in $A^{0}, \mathrm{C}_{4}$ and $\mathrm{C}_{5}$ are necessary and sufficient.

\section{Chapter II. Continuous oscillaton and convergence}

In this chapter the sequences and transformations considered may be, except in cases where a specific statement to the contrary is made, either real or complex.

We include in the following lemma a fact taken from a paper by W. A. Hurwitz.*

LEMma 4.01. If $(T)$ fails to satisfy $\mathrm{C}_{4}$, then there is a bounded sequence $\left\{s_{n}\right\}$ of constants such that

$$
\limsup _{m \rightarrow \infty, n \rightarrow \infty}\left|\sigma_{m}-\sigma_{n}\right|>\limsup _{m \rightarrow \infty}\left|s_{m}-s_{n}\right| ;
$$

if $(T)$ is real, $\left\{s_{n}\right\}$ may be taken real.

The four following lemmas may be proved together.

Lemmas 4.02, 4.03. Let $A$ be an infinite set and let $\left\{x_{\alpha}\right\}$ be a sequence of distinct points in $A$. In case $A$ has a limit point $x_{0}$, let the sequence $\left\{x_{\alpha}\right\}$ be a sequence with the limit $x_{0}$. If $(T)$, real or complex, fails to satisfy $\mathrm{C}_{5}$, then thire is a real sequence $\left\{s_{n}(x)\right\}$, bounded above (below) over $A$, such that

$$
\limsup _{\substack{m \rightarrow \infty, \infty \rightarrow \infty \\ i \rightarrow \infty, j \rightarrow \infty}}\left|\sigma_{m}\left(x_{i}\right)-\sigma_{n}\left(x_{j}\right)\right|>\limsup _{\substack{m \rightarrow \infty, n \rightarrow \infty \\ i \rightarrow \infty, j \rightarrow \infty}}\left|s_{m}\left(x_{i}^{\prime}\right)-s_{n}\left(x_{j}^{\prime}\right)\right|=0
$$

where $\left\{x_{\alpha}^{\prime}\right\}$ is any sequence of points of $A$.

* American Journal of Mathematics. 
LEMmas 4.04, 4.05. Under the hypotheses of Lemmas $4.02,4.03$ there is a real sequence $\left\{s_{n}(x)\right\}$, bounded above (below) over $A$, such that

$$
\limsup _{m \rightarrow \infty, n \rightarrow \infty, i \rightarrow \infty}\left|\sigma_{m}\left(x_{i}\right)-\sigma_{n}\left(x_{i}\right)\right|>\limsup _{m \rightarrow \infty, n \rightarrow \infty, i \rightarrow \infty}\left|s_{m}\left(x_{i}^{\prime}\right)-s_{n}\left(x_{i}^{\prime}\right)\right|=0
$$

where $\left\{x_{\alpha}^{\prime}\right\}$ is any sequence of points of $A$.

From a denial of $\mathrm{C}_{5}$ it follows that there is a value of $k$, say $\lambda$, and a sequence $\left\{n_{\alpha}\right\}$ of indices such that $\lim n_{\alpha}=+\infty$ and $a_{n_{\alpha}, \lambda} \neq 0$ for $\alpha=1,2,3, \cdots$ Define the sequence $\left\{s_{n}(x)\right\}$ as follows: $s_{n}(x)=0$ over $A$ for $n \neq \lambda ; s_{\lambda}(x)=0$ for $x \neq x_{1}, x_{2}, x_{3}, \cdots$; and $s_{\lambda}\left(x_{\alpha}\right)=(-1)^{h} /\left|a_{n_{\alpha}, \lambda}\right|$ where $h=1(h=2)$. Evidently the sequence $\left\{s_{n}(x)\right\}$ is bounded above or below over $A$ according as $h$ is 1 or 2 ; and since $s_{n}(x)=0$ over $A$ for $n>\lambda$

$$
\lim _{\substack{m \rightarrow \infty, n \rightarrow \infty \\ i \rightarrow \infty, j \rightarrow \infty}}\left|s_{m}\left(x_{i}^{\prime}\right)-s_{n}\left(x_{j}^{\prime}\right)\right|=\lim _{\substack{m \rightarrow \infty, n \rightarrow \infty \\ i \rightarrow \infty}}\left|s_{m}\left(x_{i}^{\prime}\right)-s_{n}\left(x_{i}^{\prime}\right)\right|=0
$$

where $\left\{x_{\alpha}^{\prime}\right\}$ is any sequence of points of $A$. But for $n>\lambda, \sigma_{n}\left(x_{\alpha}\right)=a_{n \lambda} s_{\lambda}\left(x_{\alpha}\right)$ and we find for $n_{\alpha}>\lambda, n_{\beta}>\lambda$ that

$$
\left|\sigma_{n_{\alpha}}\left(x_{\alpha}\right)\right|=1 \text { and }\left|\sigma_{n_{\beta}}\left(x_{\alpha}\right)\right|=\left|a_{n_{\beta, \lambda}}\right| /\left|a_{n_{\alpha}, \lambda}\right| ;
$$

hence

$$
\begin{aligned}
& \limsup _{\substack{m \rightarrow \infty, n \rightarrow \infty \\
i \rightarrow \infty, j \rightarrow \infty}}\left|\sigma_{m}\left(x_{i}\right)-\sigma_{n}\left(x_{j}\right)\right| \geqq \lim _{\substack{m \rightarrow \infty \\
m \rightarrow n \rightarrow \infty}} \sup _{\substack{i \rightarrow \infty \\
\text { ind }}}\left|\sigma_{m}\left(x_{i}\right)-\sigma_{n}\left(x_{i}\right)\right|
\end{aligned}
$$

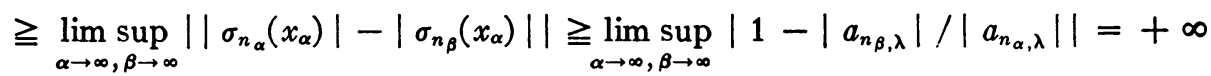

and the lemmas are proved.

\section{Oscillation OVER a SET}

Let $\left\{f_{n}(x)\right\}$ be defined over any set $A$. Then the oscillation of the sequence $\left\{f_{n}(x)\right\}$ over the set $A$ is denoted by $\Omega\left(\left\{f_{n}\right\}, A\right)$ and is defined as follows: For each sequence $\left\{x_{i}\right\}$ of points of $A$, form

$$
\lim _{\substack{m \rightarrow \infty, n \rightarrow \infty \\ i \rightarrow \infty, j \rightarrow \infty}}\left|f_{m}\left(x_{i}\right)-f_{n}\left(x_{j}\right)\right|=v ;
$$

the least upper bound of all such $v$ is $\Omega\left(\left\{f_{n}\right\}, A\right)$.

An interesting connection between the oscillation of a real sequence over a set and the ultimate bounds of the sequence over the set is given in the following. 
Lемма 4.06. If $\left\{f_{n}(x)\right\}$ is a real sequence defined over any set $A$, then

$$
\Omega\left(\left\{f_{n}\right\}, A\right)=\limsup _{n \rightarrow \infty} G\left(f_{n} ; A\right)-\liminf _{n \rightarrow \infty} g\left(f_{n} ; A\right)
$$

whenever the right member has a meaning; otherwise* $\Omega\left(\left\{f_{n}\right\}, A\right)=+\infty$.

To prove this lemma, it suffices to consider three cases: first, $f_{n}(x)$ is bounded over $A$ for all sufficiently great $n$; second, $\lim \sup G\left(f_{n} ; A\right)=+\infty$; third, $\lim \inf g\left(f_{n} ; A\right)=-\infty$. In the first case, there is a sequence $\left\{x_{i}\right\}$ of points of $A$ such that $f_{m}\left(x_{2 m}\right) \leqq G\left(f_{m}, A\right)<f_{m}\left(x_{2 m}\right)+1 / m$ and $f_{n}\left(x_{2 n+1}\right) \geqq$ $g\left(f_{n} ; A\right)>f_{n}\left(x_{2 n+1}\right)-1 / n$ for all sufficiently great $m$ and $n$; for this sequence,

$$
\limsup _{m \rightarrow \infty}\left|f_{m \rightarrow \infty}\left(x_{2 m}\right)-f_{n}\left(x_{2 n+1}\right)\right|=\limsup _{m \rightarrow \infty} G\left(f_{m} ; A\right)-\liminf _{n \rightarrow \infty} g\left(f_{n} ; A\right),
$$

so that $\Omega\left(\left\{f_{n}\right\}, A\right) \geqq \lim \sup G\left(f_{n} ; A\right)-\lim \inf g\left(f_{n} ; A\right)$. But for any sequence $\left\{x_{i}\right\}$ of points of $A, f_{m}\left(x_{i}\right) \leqq G\left(f_{m} ; A\right)$ and $f_{n}\left(x_{j}\right) \geqq g\left(f_{n} ; A\right)$ so that $\Omega\left(\left\{f_{n}\right\}, A\right)$ $\leqq \lim \sup G\left(f_{n} ; A\right)-\lim \inf g\left(f_{n} ; A\right)$. Combining inequalities, we have (4.061) for the first case. In case $\lim \sup G\left(f_{n} ; A\right)=+\infty$, let $x_{0}$ be a point of $A$, choose an index $n_{1}$ such that $G\left(f_{n_{1}} ; A\right)>f_{1}\left(x_{0}\right)+1$, and choose a point $x_{1}$ such that $f_{n_{1}}\left(x_{1}\right)>f_{1}\left(x_{0}\right)+1$; and in general choose $n_{p}$ such that $G\left(f_{n_{p}} ; A\right)$ $>f_{p}\left(x_{p-1}\right)+p$ and choose $x_{p}$ such that $f_{n_{p}}\left(x_{p}\right)>f_{p}\left(x_{p-1}\right)+p$. Then

$$
\lim _{p \rightarrow \infty}\left|f_{n_{p}}\left(x_{p}\right)-f_{p}\left(x_{p-1}\right)\right|=+\infty, \Omega\left(\left\{f_{n}\right\}, A\right)=+\infty,
$$

and the lemma is proved for the second case. In case $\lim \inf g\left(f_{n} ; A\right)=-\infty$, we can choose sequences $\left\{n_{p}\right\}$ and $\left\{x_{p}\right\}$ such that $f_{n_{p}}\left(x_{p}\right)<f_{p}\left(x_{p-1}\right)-p$, thus obtaining $\Omega\left(\left\{f_{n}\right\}, A\right)=+\infty$ and completing the proof of the lemma.

It is of interest to note specifically that this lemma enables us to use the latter theorems of $\$ 1$ to furnish easy proofs of the sufficiency (but not the necessity) of the conditions of Theorems 4.112, 4.122, 4.123, 4.132, and 4.133.

The eight theorems 4.111-4.133 give necessary and sufficient conditions that $(T)$ shall not increase oscillations of sequences over a set.

THEOREM 4.111. In order that $(T)$ may be such that

$$
\Omega\left(\left\{\sigma_{n}\right\}, A\right) \leqq \Omega\left(\left\{s_{n}\right\}, A\right)
$$

for every sequence $\left\{s_{n}(x)\right\}$, defined over an arbitrary set $A$ and bounded over $A$ for all $n, \mathrm{C}_{4}$ is necessary and sufficient.

Necessity follows from Lemma 4.01. To establish sufficiency, choose $M$ such that $\left|s_{n}(x)\right|<M$ over $A$ for all $n, B$ such that $\sum^{n}=\left|a_{n k}\right|<B$ for both $-\infty$. 
all $n$, and let $\sum_{k=1}^{n}\left|a_{n k}\right|=B_{n}$. Let $\left\{x_{i}\right\}$ be any sequence of points of $A$, and let $q$ be any number greater than $\Omega\left(\left\{s_{n}\right\}, A\right)$; then there is an index $p$ such that

(4.1112) $\left|s_{\mu}\left(x_{i}\right)-s_{\nu}\left(x_{j}\right)\right|<q$ for $\mu \geqq p, \nu \geqq p, i \geqq p, j \geqq p$.

We may write, for $m>p, n>p, i>p, j>p$, the identity

$$
\begin{aligned}
\sigma_{m}\left(x_{i}\right)-\sigma_{n}\left(x_{j}\right) & =\sum_{k=1}^{m} a_{m k} s_{k}\left(x_{i}\right)-\sum_{k=1}^{n} a_{n k} s_{k}\left(x_{j}\right) \\
& =\sum_{k=1}^{p} a_{m k} s_{k}\left(x_{i}\right)-\sum_{k=1}^{p} a_{n k} s_{k}\left(x_{j}\right)+\sum_{\mu=p+1}^{m} a_{m \mu} s_{\mu}\left(x_{i}\right)-\sum_{\nu=p+1}^{n} a_{n y} s_{\nu}\left(x_{j}\right),
\end{aligned}
$$

and, on noting that the last two terms of the last member are identically equal to

$$
\begin{gathered}
\left(\sum_{\mu=p+1}^{m} a_{m \mu} s_{\mu}\left(x_{i}\right)\right)\left(1-\sum_{\nu=p+1}^{n} a_{n \nu}\right)-\left(\sum_{\nu-p+1}^{n} a_{n \nu} s_{\nu}\left(x_{j}\right)\right)\left(1-\sum_{\mu=p+1}^{m} a_{m \mu}\right) \\
+\sum_{\mu=p+1}^{m} \sum_{\nu=p+1}^{n} a_{m \mu} a_{n \nu}\left[s_{\mu}\left(x_{i}\right)-s_{\nu}\left(x_{j}\right)\right],
\end{gathered}
$$

obtain the identity

$$
\begin{aligned}
\sigma_{m}\left(x_{i}\right)-\sigma_{n}\left(x_{j}\right) & =\sum_{k=1}^{p} a_{m k} s_{k}\left(x_{i}\right)-\sum_{k=1}^{p} a_{n k} s_{k}\left(x_{j}\right) \\
& +\left(\sum_{\mu-p+1}^{m} a_{m \mu} s_{\mu}\left(x_{i}\right)\right)\left(1-\sum_{\nu=p+1}^{n} a_{n \nu}\right) \\
& -\left(\sum_{\nu=p+1}^{n} a_{n \nu} s_{\nu}\left(x_{j}\right)\right)\left(1-\sum_{\mu-p+1}^{m} a_{m \mu}\right) \\
& +\sum_{\mu=p+1}^{m} \sum_{\nu=p+1}^{n} a_{m \mu} a_{n \nu}\left[s_{\mu}\left(x_{i}\right)-s_{\nu}\left(x_{j}\right)\right] .
\end{aligned}
$$

The absolute values of the first four terms of the right member are respectively less than or equal to

$$
M \sum_{k=1}^{p}\left|a_{m k}\right|, M \sum_{k=1}^{p}\left|a_{n k}\right|, M B\left|1-\sum_{\nu=p+1}^{n} a_{n \nu}\right| \text { and } M B\left|1-\sum_{\mu=p+1}^{m} a_{m \mu}\right|,
$$

each of which, due to the regularity of $(T)$, approaches 0 as $m$ and $n$ become infinite; hence 
$(4.1114)$

$$
\begin{aligned}
& \lim _{\substack{m \rightarrow \infty, n \rightarrow \infty \\
i \rightarrow \infty, j \rightarrow \infty}}\left|\sigma_{m}\left(x_{i}\right)-\sigma_{n}\left(x_{j}\right)\right| \\
& \quad=\lim _{\substack{m \rightarrow \infty \\
i \rightarrow \infty}} \sup _{\substack{i \rightarrow \infty \\
i \rightarrow \infty}}\left|\sum_{\mu=p+1}^{m} \sum_{\nu=p+1}^{n} a_{m \mu} a_{n \nu}\left[s_{\mu}\left(x_{i}\right)-s_{\nu}\left(x_{j}\right)\right]\right| .
\end{aligned}
$$

From (4.1112) we obtain for $m>p, n>p, i>p, j>p$,

$$
\begin{array}{r}
\left|\sum_{\mu=p+1}^{m} \sum_{\nu=p+1}^{n} a_{m \mu} a_{n \nu}\left[s_{\mu}\left(x_{i}\right)-s_{\nu}\left(x_{j}\right)\right]\right| \\
\leqq q \sum_{\mu=p+1}^{m} \sum_{\nu=p+1}^{n}\left|a_{m \mu} a_{n \nu}\right| \leqq q B_{m} B_{n} ;
\end{array}
$$

hence

$$
\limsup _{\substack{m \rightarrow \infty, n \rightarrow \infty \\ i \rightarrow \infty, j \rightarrow \infty}}\left|\sigma_{m}\left(x_{i}\right)-\sigma_{n}\left(x_{j}\right)\right| \leqq \lim _{m \rightarrow \infty, n \rightarrow \infty} \sup _{n \rightarrow \infty}\left(q B_{m} B_{n}\right)
$$

and using $\mathrm{C}_{4}$ we have

$$
\lim _{\substack{m \rightarrow \infty \\ i \rightarrow \infty, i \rightarrow \infty}} \sup _{\substack{n \rightarrow \infty \\ \text { ind }}}\left|\sigma_{m}\left(x_{i}\right)-\sigma_{n}\left(x_{j}\right)\right| \leqq q .
$$

Since $\left\{x_{i}\right\}$ is any sequence of points of $A, \Omega\left(\left\{\sigma_{n}\right\}, A\right) \leqq q$; this leads to (4.1111) and the theorem is proved.

THEOREM 4.112. In order that a real $(T)$ may be such that

$$
\Omega\left(\left\{\sigma_{n}\right\}, A\right) \leqq \Omega\left(\left\{s_{n}\right\}, A\right)
$$

for every real sequence $\left\{s_{n}(x)\right\}$, defined over an arbitrary set $A$ and bounded over $A$ for all $n, \mathrm{C}_{4}$ is necessary and sufficient.

This theorem is established by noting that the proof of the preceding theorem is undisturbed by supposing $(T)$ and the $\left\{s_{n}(x)\right\}$ sequences to be real.

THEOREM 4.121. In order that $(T)$ may be such that

$$
\Omega\left(\left\{\sigma_{n}\right\}, A\right) \leqq \Omega\left(\left\{s_{n}\right\}, A\right)
$$

for every sequence $\left\{s_{n}(x)\right\}$, defined over a finite set $A, \mathrm{C}_{4}$ is necessary and sufficient.

Necessity follows from Theorem 4.111. The condition is sufficient. If $\Omega\left(\left\{s_{n}\right\}, A\right)=+\infty$, no proof is required, for (4.1211) is automatically satisfied. If $\Omega\left(\left\{s_{n}\right\}, A\right)$ is finite, then, since $A$ is a finite set, $s_{n}(x)$ is bounded over $A$ for 
all $n$ and sufficiency follows from Theorem 4.111. This argument, based on Theorem 4.112, establishes

THEOREM 4.122. In order that a real $(T)$ may be such that

$$
\Omega\left(\left\{\sigma_{n}\right\}, A\right) \leqq \Omega\left(\left\{s_{n}\right\}, A\right)
$$

for every real sequence $\left\{s_{n}(x)\right\}$, defined over a finite set $A, C_{1}$ is necessary and sufficient.

From Theorems 4.112 and 4.122 we obtain

THEOREM 4.123. In order that a real $(T)$ may be such that

$$
\Omega\left(\left\{\sigma_{n}\right\}, A\right) \leqq \Omega\left(\left\{s_{n}\right\}, A\right)
$$

for every real sequence $\left\{s_{n}(x)\right\}$, defined over a finite set $A$ and bounded above (below) over $A$ for all $n, \mathrm{C}_{4}$ is necessary and sufficient.

THEOREM 4.131. In order that $(T)$ may be such that

$$
\Omega\left(\left\{\sigma_{n}\right\}, A\right) \leqq \Omega\left(\left\{s_{n}\right\}, A\right)
$$

for every sequence $\left\{s_{n}(x)\right\}$, defined over an infinite set $A, C_{4}$ and $\mathrm{C}_{5}$ are necessary and sufficient.

Necessity of $C_{4}$ follows from Lemma 4.01, and that of $C_{5}$ from Lemma 4.02 (or 4.03), since for the $\left\{s_{n}(x)\right\}$ sequences there defined, $\Omega\left(\left\{s_{n}\right\}, A\right)=0$ while $\Omega\left(\left\{\sigma_{n}\right\}, A\right)>0$. No proof of sufficiency is required if $\Omega\left(\left\{s_{n}\right\}, A\right)=+\infty$. If $\Omega\left(\left\{s_{n}\right\}, A\right)$ is finite, let $q$ be any greater number, let $\left\{x_{i}\right\}$ be any sequence of points of $A$, and choose an index $p$ such that (4.1112) is satisfied. Then $\left|s_{n}\left(x_{i}\right)-s_{p}\left(x_{p}\right)\right|<q$ for $n \geqq p, i \geqq p$; hence there is a constant $M$ such that $\left|s_{n}\left(x_{i}\right)\right|<M$ for $n \geqq p, i \geqq p$. Using $\mathrm{C}_{5}$, choose an index $N \geqq p$ such that $a_{n k}=0, k=1,2,3, \cdots, p$ for $n>N$. Then, referring to the identity (4.1113), we see that, for $m>N, n>N, i>p, j>p$, the first two terms of the right member vanish and the third and fourth terms approach 0 as $m$ and $n$ become infinite. Therefore we may write (4.1114) and (4.1115), and sufficiency follows as in Theorem 4.111.

The same proof establishes the following two theorems:

TheOREM 4.132. In order that a real $(T)$ may be such that

$$
\Omega\left(\left\{\sigma_{n}\right\}, A\right) \leqq \Omega\left(\left\{s_{n}\right\}, A\right)
$$

for every real sequence $\left\{s_{n}(x)\right\}$, defined over an infinite set $A, \mathrm{C}_{4}$ and $\mathrm{C}_{5}$ are necessary and sufficient. 
THEOREM 4.133. In order that a real $(T)$ may be such that

$$
\Omega\left(\left\{\sigma_{n}\right\}, A\right) \leqq \Omega\left(\left\{s_{n}\right\}, A\right)
$$

for every real sequence $\left\{s_{n}(x)\right\}$, defined over an infinite set $A$ and bounded above (below) over $A$ for all $n, \mathrm{C}_{\star}$ and $\mathrm{C}_{5}$ are necessary and sufficient.

The five theorems 4.21-4.233 give necessary and sufficient conditions that $(T)$ shall transform sequerces of zero oscillation into sequences of zero oscillation.

Theorem 4.21. In order that $(T)$ may be such that $\Omega\left(\left\{\sigma_{n}\right\}, A\right)=0$ for every sequence $\left\{s_{n}(x)\right\}$, defined over an arbitrary set $A$ and bounded over $A$ for all $n$, such that $\Omega\left(\left\{s_{n}\right\}, A\right)=0$, no further conditions need be imposed upon $a_{n k}$.

Letting $\left\{x_{i}\right\}$ be any sequence of points of $A$, and $q$ be an arbitrarily small positive number, we can choose an index $p$ for which (4.1112) holds; and using (4.1113) obtain (4.1116) precisely as in Theorem 4.111. But

$$
\lim _{m \rightarrow \infty, n \rightarrow \infty} \sup _{m}\left(q B_{m} B_{n}\right) \leqq q B^{2} ;
$$

hence $\Omega\left(\left\{\sigma_{n}\right\}, A\right) \leqq q B^{2}$. Since $q B^{2}$ is an arbitrarily small positive number, $\Omega\left(\left\{\sigma_{n}\right\}, A\right)=0$ and the theorem is proved.

THEOREM 4.22. In order that $(T)$ may be such that $\Omega\left(\left\{\sigma_{n}\right\}, A\right)=0$ for every sequence $\left\{s_{n}(x)\right\}$, defined over a finite set $A$, such that $\Omega\left(\left\{s_{n}\right\}, A\right)=0$, no further conditions need be imposed on $a_{n k}$.

This theorem follows from the preceding, for if $\Omega\left(\left\{s_{n}\right\}, A\right)=0, A$ being a finite set, then $s_{n}(x)$ is bounded over $A$ for all $n$.

THEOREM 4.231. In order that $(T)$ may be such that $\Omega\left(\left\{\sigma_{n}\right\}, A\right)=0$ for every sequence $\left\{s_{n}(x)\right\}$, defined over an infinite set $A$, such that $\Omega\left(\left\{s_{n}\right\}, A\right)=0$, $\mathrm{C}_{5}$ is necessary and sufficient.

Necessity follows from Lemma 4.02 (or 4.03 ). The sufficiency proof is a modification of that of Theorem 4.131 in the same sense that the proof of Theorem 4.21 is a modification of the sufficiency proof of Theorem 4.111. This proof also establishes the following two theorems:

Theorem 4.232. In order that a real $(T)$ may be such that $\Omega\left(\left\{\sigma_{n}\right\}, A\right)=0$ for every real sequence $\left\{s_{n}(x)\right\}$, defined over an infinite set $A$, such that $\Omega\left(\left\{s_{n}\right\}, A\right)$ $=0, \mathrm{C}_{5}$ is necessary and sufficient.

THEOREM 4.233. In order that a real $(T)$ may be such that $\Omega\left(\left\{\sigma_{n}\right\}, A\right)=0$ for every real sequence $\left\{s_{n}(x)\right\}$, defined over an infinite set $A$ and bounded above (below) over $A$ for all $n$, such that $\Omega\left(\left\{s_{n}\right\}, A\right)=0, \mathrm{C}_{5}$ is necessary and sufficient. 


\section{Continuous oscillation AND CONVERgenCe AT A POINT}

Let $\left\{f_{n}(x)\right\}$ be defined over a set $A$ and let $x_{0}$ be a point of $A^{0}$. Then the continuous oscillation of $\left\{f_{n}(x)\right\}$ at $x_{0}$ over $A$ is denoted by $\Omega\left(x_{0} ;\left\{f_{n}\right\}, A\right)$ and is defined as follows: For each sequence $\left\{x_{i}\right\}$ of points of $A$ with the limit $x_{0}$, form

$$
\lim _{\substack{m \rightarrow \infty, \\ \text { sup } \\ i \rightarrow \infty, j \rightarrow \infty}}\left|f_{m}\left(x_{i}\right)-f_{n}\left(x_{j}\right)\right|=v ;
$$

the least upper bound of all such $v$ is $\Omega\left(x_{0} ;\left\{f_{n}\right\}, A\right)$. A sequence $\left\{f_{n}(x)\right\}$ is said to converge continuously at $x_{0}$ over $A$ when $\Omega\left(x_{0} ;\left\{f_{n}\right\}, A\right)=0$. We may consider $\Omega\left(x_{0} ;\left\{f_{n}\right\}, A\right)$ as a measure of the deviation from continuous convergence of $\left\{f_{n}(x)\right\}$ at $x_{0}$ over $A$; hence the relation $\Omega\left(x_{0} ;\left\{\sigma_{n}\right\}, A\right) \leqq \Omega\left(x_{0}\right.$; $\left.\left\{s_{n}\right\}, A\right)$ signifies that $\left\{\sigma_{n}(x)\right\}$ is at least as nearly continuously convergent at $x_{0}$ over $A$ as $\left\{s_{n}(x)\right\}$ is. The continuous oscillation of a real sequence at a point is related to the ultimate bounds of the sequence at the point by the following lemma, the proof of which is similar to that of Lemma 4.06.

Lемма 5.01. If $\left\{f_{n}(x)\right\}$ is a real sequence defined over a set $A$ such that $x_{0}$ is in $A^{0}$, then

$$
\Omega\left(x_{0} ;\left\{f_{n}\right\}, A\right)=\Gamma\left(x_{0} ;\left\{f_{n}\right\}, A\right)-\gamma\left(x_{0} ;\left\{f_{n}\right\}, A\right) *
$$

whenever the right member has a meaning; otherwise $\Omega\left(x_{0} ;\left\{f_{n}\right\}, A\right)=+\infty$.

Using this lemma, we may note that the theorems of this section which involve real transformations and sequences are related to the latter theorems of $\$ 2$ as the corresponding theorems of $\$ 4^{\circ}$ are related to the latter theorems of $\$ 1$.

The eight theorems 5.111-5.133 give necessary and sufficient conditions that $(T)$ shall not increase the continuous oscillation of a sequence at a point.

THEOREM 5.111. In order that $(T)$ may be such that

$$
\Omega\left(x_{0} ;\left\{\sigma_{n}\right\}, A\right) \leqq \Omega\left(x_{0} ;\left\{s_{n}\right\}, A\right)
$$

for every sequence $\left\{s_{n}(x)\right\}$, defined over a set $A$ such that $x_{0}$ is in $A^{0}$ and bounded over a neighborhood $D$ of $x_{0}$ in $A$ for all $n, \mathrm{C}_{4}$ is necessary and sufficient.

Necessity follows from Lemma 4.01. To establish sufficiency, choose $M$ such that $\left|s_{n}(x)\right|<M$ over $D$ for all $n$, let $\left\{x_{i}\right\}$ be any sequence of points of $A$ with the limit $x_{0}$, and let $q$ be any number greater than $\Omega\left(x_{0} ;\left\{s_{n}\right\}, A\right)$. Then there is an index $p$ for which (4.1112) holds; let $p$ be increased if necessary

* For real sequences $\Omega\left(x_{0} ;\left\{f_{n}\right\}, A\right)$ is sometimes defined by this relation. Hahn, p. 261. 
so that $x_{i}$ is in $D$ for $i>p$. Using (4.1113), we obtain (4.1117) exactly as in Theorem 4.111; therefore $\Omega\left(x_{0} ;\left\{\sigma_{n}\right\}, A\right) \leqq q$ and sufficiency follows. The same proof establishes

THEOREM 5.112. In order that a real $(T)$ may be such that

$$
\Omega\left(x_{0} ;\left\{\sigma_{n}\right\}, A\right) \leqq \Omega\left(x_{0} ;\left\{s_{n}\right\}, A\right)
$$

for every real sequence $\left\{s_{n}(x)\right\}$, defined over a set $A$ such that $x_{0}$ is in $A^{0}$ and bounded over a neighborhood $D$ of $x_{0}$ in $A$ for all $n, C$, is necessary and sufficient.

The next two theorems result from the preceding two, for if $\Omega\left(x_{0} ;\left\{s_{n}\right\}, A\right)$ is finite and $x_{0}$ is an isolated point of $A$, then $s_{n}(x)$ is bounded over a neighborhood $D$ of $x_{0}$ in $A$ for all $n$.

THEOREM 5.121. In order that $(T)$ may be such that

$$
\Omega\left(x_{0} ;\left\{\sigma_{n}\right\}, A\right) \leqq \Omega\left(x_{0} ;\left\{s_{n}\right\}, A\right)
$$

for every sequence $\left\{s_{n}(x)\right\}$, defined over a set $A$ of which $x_{0}$ is an isolated point, $\mathrm{C}_{\mathrm{A}}$ is necessary and sufficient.

THEOREM 5.122. In order that a real $(T)$ may be such that

$$
\Omega\left(x_{0} ;\left\{\sigma_{n}\right\}, A\right) \leqq \Omega\left(x_{0} ;\left\{s_{n}\right\}, A\right)
$$

for every real sequence $\left\{s_{n}(x)\right\}$, defined over a set $A$ of which $x_{0}$ is an isolated point, $\mathrm{C}_{4}$ is necessary and sufficient.

From Theorems 5.112 and 5.122 we obtain

THEOREM 5.123. In order that a real (T) may be such that

$$
\Omega\left(x_{0} ;\left\{\sigma_{n}\right\}, A\right) \leqq \Omega\left(x_{0} ;\left\{s_{n}\right\}, A\right)
$$

for every real sequence $\left\{s_{n}(x)\right\}$, defined over a set $A$ of which $x_{0}$ is an isolated point and bounded above (below) over a neighborhood $D$ of $x_{0}$ in $A$ for all $n$, $\mathrm{C}_{4}$ is necessary and sufficient.

THEOREM 5.131. In order that $(T)$ may be such that

$$
\Omega\left(x_{0} ;\left\{\sigma_{n}\right\}, A\right) \leqq \Omega\left(x_{0} ;\left\{s_{n}\right\}, A\right)
$$

for every sequence $\left\{s_{n}(x)\right\}$, defined over a set $A$ of which $x_{0}$ is a limit point, $C_{4}$ and $\mathrm{C}_{5}$ are necessary and suficient.

The proof of this theorem is a modification of that of Theorem 4.131 in the same sense that the proof of Theorem 5.111 is a modification of that of Theorem 4.111. The same proof establishes the next two theorems. 
THEOREM 5.132. In order that a real $(T)$ may be such that

$$
\Omega\left(x_{0} ;\left\{\sigma_{n}\right\}, A\right) \leqq \Omega\left(x_{0} ;\left\{s_{n}\right\}, A\right)
$$

for every real sequence $\left\{s_{n}(x)\right\}$, defined over a set $A$ of which $x_{0}$ is a limit point, $\mathrm{C}_{4}$ and $\mathrm{C}_{5}$ are necessary and sufficient.

Theorem 5.133. In order that $(T)$ may be such that

$$
\Omega\left(x_{0} ;\left\{\sigma_{n}\right\}, A\right) \leqq \Omega\left(x_{0} ;\left\{s_{n}\right\}, A\right)
$$

for every real sequence $\left\{s_{n}(x)\right\}$, defined over a set $A$ of which $x_{0}$ is a limit point and bounded above (below) over a neighborhood $D$ of $x_{0}$ in $A$ for all $n, \mathrm{C}_{4}$ and $\mathrm{C}_{5}$ are necessary and sufficient.

The five theorems 5.21-5.233, the proofs of which are modifications of the proofs of the corresponding theorems of $\$ 4$, give necessary and sufficient conditions that $(T)$ shall transform sequences which converge continuously at a point into sequences which converge continuously at the point.

TheOREM 5.21. In order that $(T)$ may be such that $\Omega\left(x_{0} ;\left\{\sigma_{n}\right\}, A\right)=0$ for every sequence $\left\{s_{n}(x)\right\}$, defined over a set $A$ such that $x_{0}$ is in $A^{0}$ and bounded over a neighborhood $D$ of $x_{0}$ in $A$ for all $n$, such that $\Omega\left(x_{0} ;\left\{s_{n}\right\}, A\right)=0$, no further conditions need be imposed on $a_{n k}$.

Theorem 5.22. In order that $(T)$ may be such that $\Omega\left(x_{0} ;\left\{\sigma_{n}\right\}, A\right)=0$ for every sequence $\left\{s_{n}(x)\right\}$, defined over a set $A$ of which $x_{0}$ is an isolated point, such that $\Omega\left(x_{0} ;\left\{s_{n}\right\}, A\right)=0$, no further conditions need be imposed on $a_{n k}$.

Theorem 5.231. In order that $(T)$ may be such that $\Omega\left(x_{0} ;\left\{\sigma_{n}\right\}, A\right)=0$ for every sequence $\left\{s_{n}(x)\right\}$, defined over a set $A$ of which $x_{0}$ is a limit point, such that $\Omega\left(x_{0} ;\left\{s_{n}\right\}, A\right)=0, \mathrm{C}_{5}$ is necessary and sufficient.

TheOREM 5.232. In order that a real $(T)$ may be such that $\Omega\left(x_{0} ;\left\{\sigma_{n}\right\}, A\right)=0$ for every real sequence $\left\{s_{n}(x)\right\}$, defined over a set $A$ of which $x_{0}$ is a limit point, such that $\Omega\left(x_{0} ;\left\{s_{n}\right\}, A\right)=0, \mathrm{C}_{5}$ is necessary and sufficient.

TheOREM 5.233. In order that a real $(T)$ may be such that $\Omega\left(x_{0} ;\left\{\sigma_{n}\right\}, A\right)=0$ for every real sequence $\left\{s_{n}(x)\right\}$, defined over a set $A$ of which $x_{0}$ is a limit point and bounded above (below) over a neighborhood $D$ of $x_{0}$ in $A$ for all $n$, such that $\Omega\left(x_{0} ;\left\{s_{n}\right\}, A\right)=0, \mathrm{C}_{5}$ is necessary and sufficient.

\section{Continuous oscillation and Convergence at}

ALL POINTS AND LIMIT POINTS OF A SET

In comparing the theorems of this section with those of $\$ 4$, the following facts, included as lemmas, should be noted. 
LEMma 6.01. If $\Omega\left(\left\{f_{n}\right\}, A\right) \leqq \Omega\left(\left\{F_{n}\right\}, A\right)$ where $A$ contains more than one point, then it is not necessarily true that $\Omega\left(x ;\left\{f_{n}\right\}, A\right) \leqq \Omega\left(x ;\left\{F_{n}\right\}, A\right)$ over $A$.

This lemma is established by considering the following simple sequences. Let $x_{1}$ and $x_{2}$ be two points of $A$ and define $f_{n}\left(x_{1}\right)=(-1)^{n}, f_{n}(x)=0$ for $x \neq x_{1}$, and $F_{n}\left(x_{2}\right)=(-1)^{n}, F_{n}(x)=0$ for $x \neq x_{2}$.

From the definitions of the functions involved we obtain at once

LEMMA 6.02. If $\Omega\left(\left\{f_{n}\right\}, A\right)=0, A$ being an arbitrary set, then $\Omega\left(x ;\left\{f_{n}\right\}, A\right)$ $=0$ over $A^{0}$.

Lemma 6.03. If $\Omega\left(x ;\left\{f_{n}\right\}, A\right) \leqq \Omega\left(x ;\left\{F_{n}\right\}, A\right)$ over $A^{0}$ and $A$ is compact, then $\Omega\left(\left\{f_{n}\right\}, A\right) \leqq \Omega\left(\left\{F_{n}\right\}, A\right)$.

Suppose $A$ is compact and $\Omega\left(\left\{f_{n}\right\}, A\right)>\Omega\left(\left\{F_{n}\right\}, A\right)$; we shall show that the hypothesis is contradicted. Choose a sequence $\left\{x_{i}\right\}$ of points of $A$ and four sequences $\left\{m_{\alpha}\right\},\left\{n_{\alpha}\right\},\left\{i_{\alpha}\right\}$ and $\left\{j_{\alpha}\right\}$ of indices such that

$$
\lim _{\alpha \rightarrow \infty}\left|f_{m_{\alpha}}\left(x_{i_{\alpha}}\right)-f_{n_{\alpha}}\left(x_{j_{\alpha}}\right)\right|=\Omega\left(\left\{f_{n}\right\}, A\right) .
$$

Since $A$ is compact, let $\left\{x_{i}^{\prime}\right\}$ be a subsequence of $\left\{x_{i}\right\}$ with a limit, say $x_{0}$; then $\Omega\left(x_{0} ;\left\{f_{n}\right\}, A\right) \geqq \Omega\left(\left\{f_{n}\right\}, A\right)$. It follows at once from the definitions of the functions involved that $\Omega\left(\left\{F_{n}\right\}, A\right) \geqq \Omega\left(x ;\left\{F_{n}\right\}, A\right)$ over $A^{0}$ and we find on combining inequalities that $\Omega\left(x_{0} ;\left\{f_{n}\right\}, A\right)>\Omega\left(x ;\left\{F_{n}\right\}, A\right)$ over $A^{0}$; thus the hypothesis is contradicted and the lemma is proved. If in this lemma we set $F_{n}(x)=0$ over $A$ for all $n$ we obtain

Lemma 6.04. If $\Omega\left(x ;\left\{f_{n}\right\}, A\right)=0$ over $A^{0}$ and $A$ is compact, then $\Omega\left(\left\{f_{n}\right\}, A\right)=0$.

The condition " $A$ is compact" cannot be removed" from Lemma 6.04 and it follows that it cannot be removed from Lemma 6.03.

The theorems of this section are obtained from those of $\$ 5$ as theorems of $\$ 3$ are obtained from $\$ 2$.

The eight theorems 6.111-6.133 give necessary and sufficient conditions that $(T)$ shall not increase the continuous oscillations of sequences at the points and limit points of a set.

* To show this, let $\left\{x_{n}\right\}$ be a sequence of points of $A$ without limit points and define $f_{n}\left(x_{n}\right)=1$ and $f_{n}(x)=0, x \neq x_{n}$; then $\Omega\left(x ;\left\{f_{n}\right\}, A\right)=0$ over $A^{0}, \Omega\left(\left\{f_{n}\right\}, A\right)=1$, and the lemma fails. 
THEOREM 6.111. In order that $(T)$ may be such that

$$
\Omega\left(x ;\left\{\sigma_{n}\right\}, A\right) \leqq \Omega\left(x ;\left\{s_{n}\right\}, A\right) \text { over } A^{0}
$$

for every sequence $\left\{s_{n}(x)\right\}$, defined over an arbitrary set $A$, and bounded over $A$ for all $n, \mathrm{C}_{4}$ is necessary and sufficient.

TheOREM 6.112. In order that a real $(T)$ may be such that

$$
\Omega\left(x ;\left\{\sigma_{n}\right\}, A\right) \leqq \Omega\left(x ;\left\{s_{n}\right\}, A\right) \text { over } A^{0}
$$

for every real sequence $\left\{s_{n}(x)\right\}$, defined over an arbitrary set $A$ and bounded over $A$ for all $n, \mathrm{C}_{4}$ is necessary and sufficient.

THEOREM 6.121. In order that $(T)$ may be such that

$$
\Omega\left(x ;\left\{\sigma_{n}\right\}, A\right) \leqq \Omega\left(x ;\left\{s_{n}\right\}, A\right) \text { over } A
$$

for every sequence $\left\{s_{n}(x)\right\}$, defined over a set $A$ without limit points, $C_{1}$ is necessary and sufficient.

THEOREM 6.122. In order that a real $(T)$ may be such that

$$
\Omega\left(x ;\left\{\sigma_{n}\right\}, A\right) \leqq \Omega\left(x ;\left\{s_{n}\right\}, A\right) \text { over } A
$$

for every real sequence $\left\{s_{n}(x)\right\}$, defined over a set $A$ without limit points, $\mathrm{C}_{4}$ is necessary and sufficient.

THEOREM 6.123. In order that a real $(T)$ may be such that

$$
\Omega\left(x ;\left\{\sigma_{n}\right\}, A\right) \leqq \Omega\left(x ;\left\{s_{n}\right\}, A\right) \text { over } A
$$

for every real sequence $\left\{s_{n}(x)\right\}$, defined over a set $A$ without limit points and bounded above (below) over $A$ for all $n, \mathrm{C}_{4}$ is necessary and sufficient.

THEOREM 6.131. In order that $(T)$ may be such that

$$
\Omega\left(x ;\left\{\sigma_{n}\right\}, A\right) \leqq \Omega\left(x ;\left\{s_{n}\right\}, A\right) \text { over } A^{0}
$$

for every sequence $\left\{s_{n}(x)\right\}$, defined over a set $A$ with at least one limit point, $\mathrm{C}_{\text {. }}$ and $\mathrm{C}_{5}$ are necessary and sufficient.

THEOREM 6.132. In order that a real $(T)$ may be such that

$$
\Omega\left(x ;\left\{\sigma_{n}\right\}, A\right) \leqq \Omega\left(x ;\left\{s_{n}\right\}, A\right) \text { over } A^{0}
$$

for every real sequence $\left\{s_{n}(x)\right\}$, defined over a set $A$ with at least one limit point, $\mathrm{C}_{4}$ and $\mathrm{C}_{5}$ are necessary and sufficient. 
THEOREM 6.133. In order that a real $(T)$ may be such that

$$
\Omega\left(x ;\left\{\sigma_{n}\right\}, A\right) \leqq \Omega\left(x ;\left\{s_{n}\right\}, A\right) \text { over } A^{0}
$$

for every real sequence $\left\{s_{n}(x)\right\}$, defined over a set $A$ with at least one limit point and bounded above (below) over $A$ for all $n, \mathrm{C}_{4}$ and $\mathrm{C}_{5}$ are necessary and sufficient.

The five theorems 6.21-6.233 give necessary and sufficient conditions that $(T)$ shall transform sequences which converge continuously at each point and limit point of a set into sequences having the same property.

THEOREM 6.21. In order that $(T)$ may be such that $\Omega\left(x ;\left\{\sigma_{n}\right\}, A\right)=0$ over $A^{0}$ for every sequence $\left\{s_{n}(x)\right\}$, defined over an arbitrary set $A$ and bounded in the neighborhood of each point of $A^{0}$ for all $n$, such that $\Omega\left(x ;\left\{s_{n}\right\}, A\right)=0$ over $A^{0}$, no further conditions need be imposed on $a_{n k}$.

TheOREM 6.22. In order that $(T)$ may be such that $\Omega\left(x ;\left\{\sigma_{n}\right\}, A\right)=0$ over $A$ for every sequence $\left\{s_{n}(x)\right\}$, defined over a set $A$ without limit points, such that $\Omega\left(x ;\left\{s_{n}\right\}, A\right)=0$ over $A$, no further conditions need be imposed on $a_{n k}$.

TheOREM 6.231. In order that $(T)$ may be such that $\Omega\left(x ;\left\{\sigma_{n}\right\}, A\right)=0$ over $A^{0}$ for every sequence $\left\{s_{n}(x)\right\}$, defined over a set $A$ with at least one limit point such that $\Omega\left(x ;\left\{s_{n}\right\}, A\right)=0$ over $A^{0}, \mathrm{C}_{5}$ is necessary and sufficient.

THEOREM 6.232. In order that a real $(T)$ may be such that $\Omega\left(x ;\left\{\sigma_{n}\right\}, A\right)=0$ over $A^{0}$ for every real sequence $\left\{s_{n}(x)\right\}$, defined over a set $A$ with at least one limit point, such that $\Omega\left(x ;\left\{s_{n}\right\}, A\right)=0$ over $A^{0}, \mathrm{C}_{5}$ is necessary and sufficient.

THEOREM 6.233. In order that a real $(T)$ may be such that $\Omega\left(x ;\left\{\sigma_{n}\right\}, A\right)=0$ over $A^{0}$ for every real sequence $\left\{s_{n}(x)\right\}$, defined over a set $A$ with at least one limit point and bounded above (below) over $A$ for all $n$, such that $\Omega\left(x ;\left\{s_{n}\right\}, A\right)=0$ over $A^{0}, \mathrm{C}_{5}$ is necessary and sufficient.

\section{Chapter III. UNIForm OSCillation AND CONVERGENCE}

In this chapter the transformations and sequences may, except in cases where a specific statement to the contrary is made, be either real or complex.

We shall now prove together

LEMmas 7.01, 7.02. Let $A$ be an infinite set and let $\left\{x_{\alpha}\right\}$ be a sequence of distinct points of $A$. In case $A$ has a limit point $x_{0}$, let $\left\{x_{\alpha}\right\}$ have the limit $x_{0}$. If $(T)$, real or complex, fails to satisfy $\mathrm{C}_{6}$, then there is a real sequence $\left\{s_{n}(x)\right\}$ bounded above (below) over $A$ such that

$$
\limsup _{m \rightarrow \infty ; n \rightarrow \infty, i \rightarrow \infty}\left|\sigma_{m}\left(x_{i}\right)-\sigma_{n}\left(x_{i}\right)\right|>\limsup _{m \rightarrow \infty, n \rightarrow \infty, i \rightarrow \infty}\left|s_{m}\left(x_{i}^{\prime}\right)-s_{n}\left(x_{i}^{\prime}\right)\right|=0
$$

where $\left\{x_{i}^{\prime}\right\}$ is any sequence of points of $A$. 
From a denial of $\mathrm{C}_{b}$ it follows that there is a sequence $\left\{n_{\alpha}\right\}$ such that

$$
\lim _{\alpha \rightarrow \infty} n_{\alpha}=+\infty \text { and } \sum_{k=1}^{n_{\alpha}} a_{n_{\alpha, k}} \neq 1 \text { for } \alpha=1,2,3, \cdots .
$$

Define a real function $s(x)$ over $A$, bounded above (below) over $A$ such that

$$
s\left(x_{\alpha}\right)=(-1)^{h} /\left|1-\sum_{k=1}^{n_{\alpha}} a_{n_{\alpha, k}}\right|
$$

where $h=1(2)$; and let $s_{n}(x)=s(x), n=1,2,3, \cdots$. Then $s_{n}(x)$ is bounded above (below) over $A$ for all $n$; and $s_{m}(x)-s_{n}(x)=0$ over $A$ so that

$$
\limsup _{m \rightarrow \infty, n \rightarrow \infty, i \rightarrow \infty}\left|s_{m}\left(x_{i}^{\prime}\right)-s_{n}\left(x_{i}^{\prime}\right)\right|=0
$$

where $\left\{x_{i}^{\prime}\right\}$ is any sequence of points of $A$. But

$$
\begin{aligned}
& \limsup _{m \rightarrow \infty, n \rightarrow \infty, i \rightarrow \infty}\left|\sigma_{m}\left(x_{i}\right)-\sigma_{n}\left(x_{i}\right)\right|=\limsup _{m \rightarrow \infty, n \rightarrow \infty, i \rightarrow \infty}\left(\left|s\left(x_{i}\right)\right|\left|\sum_{k=\cdot}^{m} a_{m k}-\sum_{k=1}^{n} a_{n k}\right|\right) \\
& \geqq \limsup _{n \rightarrow \infty, i \rightarrow \infty}\left(\left|s\left(x_{i}\right)\right|\left|1-\sum_{k=1}^{n} a_{n k}\right|\right) \geqq \limsup _{\alpha \rightarrow \infty}\left(\left|s\left(x_{\alpha}\right)\right|\left|1-\sum_{k=1}^{n_{\alpha}} a_{n_{\alpha, k}}\right|\right)=1
\end{aligned}
$$

and the lemmas are proved.

\section{UNIFORM OSCILLATION AND CONVERGENCE OVER A SET}

Let $\left\{f_{n}(x)\right\}$ be defined over any set $A$. Then the uniform oscillation of the sequence $\left\{f_{n}(x)\right\}$ over the set $A$ is denoted by $O\left(\left\{f_{n}\right\}, A\right)$ and is defined as follows: For each sequence $\left\{x_{i}\right\}$ of points of $A$, form

$$
\limsup _{m \rightarrow \infty, n \rightarrow \infty, i \rightarrow \infty}\left|f_{m}\left(x_{i}\right)-f_{n}\left(x_{i}\right)\right|=v ;
$$

the least upper bound of all such $v$ is $O\left(\left\{f_{n}\right\}, A\right)$. It is well known that a necessary and sufficient condition that a sequence $\left\{f_{n}(x)\right\}$ converge uniformly over a set $A$ is that $O\left(\left\{f_{n}\right\}, A\right)=0$. We may consider $O\left(\left\{f_{n}\right\}, A\right)$ as a measure of the deviation from uniform convergence of $\left\{f_{n}(x)\right\}$ over $A$; hence the relation $O\left(\left\{\sigma_{n}\right\}, A\right) \leqq O\left(\left\{s_{n}\right\}, A\right)$ signifies that $\left\{\sigma_{n}(x)\right\}$ is at least as nearly uniformly convergent over $A$ as $\left\{s_{n}(x)\right\}$ is.

The eight theorems 7.111-7.133 give necessary and sufficient conditions that $(T)$ shall not increase uniform oscillations of sequences over a set.

THEOREM 7.111. In order that $(T)$ may be such that

$$
O\left(\left\{\sigma_{n}\right\}, A\right) \leqq O\left(\left\{s_{n}\right\}, A\right)
$$

for every sequence $\left\{s_{n}(x)\right\}$, defined over an arbitrary set $A$ and bounded over $A$ for all $n, \mathrm{C}_{4}$ is necessary and sufficient. 
Necessity follows from Lemma 4.01. The sufficiency proof is verbatim that of Theorem 4.111 except that $j$ is replaced by $i$ and that the $\Omega$-function is replaced by the $O$-function. The same proof establishes

Theorem 7.112. In order that a real $(T)$ may be such that

$$
O\left(\left\{\sigma_{n}\right\}, A\right) \leqq O\left(\left\{s_{n}\right\}, A\right)
$$

for every real sequence $\left\{s_{n}(x)\right\}$, defined over an arbitrary set $A$ and bounded over $A$ for all $n, \mathrm{C}_{4}$ is necessary and sufficient.

Noting that if $O\left(\left\{s_{n}\right\}, A\right)$ is finite and $A$ is a finite set, then $s_{n}(x)$ is bounded over $A$ for all $n$, we obtain the next three theorems.

THEOREM 7.121. In order that $(T)$ may be such that

$$
O\left(\left\{\sigma_{n}\right\}, A\right) \leqq O\left(\left\{s_{n}\right\}, A\right)
$$

for every sequence $\left\{s_{n}(x)\right\}$, defined over a finite set $A, \mathrm{C}_{4}$ is necessary and sufficient.

THEOREM 7.122. In order that a real $(T)$ may be such that

$$
O\left(\left\{\sigma_{n}\right\}, A\right) \leqq O\left(\left\{s_{n}\right\}, A\right)
$$

for every real sequence $\left\{s_{n}(x)\right\}$, defined over a finite set $A, C_{4}$ is necessary and sufficient.

THEOREM 7.123. In order that a real $(T)$ may be such that

$$
O\left(\left\{\sigma_{n}\right\}, A\right) \leqq O\left(\left\{s_{n}\right\}, A\right)
$$

for every real sequence $\left\{s_{n}(x)\right\}$, defined over a finite set $A$ and bounded above (below) over $A$ for all $n, C_{4}$ is necessary and sufficient.

THEOREM 7.131. In order that $(T)$ may be such that

$$
O\left(\left\{\sigma_{n}\right\}, A\right) \leqq O\left(\left\{s_{n}\right\}, A\right)
$$

for every sequence $\left\{s_{n}(x)\right\}$, defined over an infinite set $A, \mathrm{C}_{4}, \mathrm{C}_{5}$ and $\mathrm{C}_{6}$ are necessary and sufficient.

The necessity of $C_{4}$ follows from Lemma 4.01 ; that of $C_{5}$ and $C_{6}$ from Lemmas 4.04 or 4.05 and 7.01 or 7.02 respectively since for the sequences there defined, $O\left(\left\{s_{n}\right\}, A\right)=0$ while $O\left(\left\{\sigma_{n}\right\}, A\right)>0$. If $O\left(\left\{s_{n}\right\}, A\right)=+\infty$, no proof of sufficiency is required. If $O\left(\left\{s_{n}\right\}, A\right)$ is finite, let $q$ be any greater number and let $\left\{x_{i}\right\}$ be any sequence of points of $A$; then there is an index $p$ such that $\left|s_{\mu}\left(x_{i}\right)-s_{\nu}\left(x_{i}\right)\right|<q$ for $\mu>p, \nu>p, i>p$. Using $\mathrm{C}_{5}$ and $\mathrm{C}_{6}$ we can choose an index $N$ such that $a_{n k}=0, k=1,2,3, \cdots, p$ for $n>N$ and 
also $\sum_{k=p+1}^{n} a_{n k}=1$ for $n>N$. Then, considering the identity (4.1113) with $j$ replaced by $i$, the first four terms of the right member vanish for $m>N$, $n>N$; hence we obtain successively (4.1114), (4.1115), (4.1116), and, using $\mathrm{C}_{4},(4.1117)$ with $j$ replaced by $i$. Therefore $O\left(\left\{\sigma_{n}\right\}, A\right) \leqq q, O\left(\left\{\sigma_{n}\right\}, A\right)$ $\leqq O\left(\left\{s_{n}\right\}, A\right)$ and the theorem is proved. The same proof establishes the next two theorems.

ThEOREM 7.132. In order that a real (T) may be such that

$$
O\left(\left\{\sigma_{n}\right\}, A\right) \leqq O\left(\left\{s_{n}\right\}, A\right)
$$

for every real sequence $\left\{s_{n}(x)\right\}$, defined over an infinite set $A, \mathrm{C}_{4}, \mathrm{C}_{5}$ and $\mathrm{C}_{6}$ are necessary and sufficient.

THEOREM 7.133. In order that a real $(T)$ may be such that

$$
O\left(\left\{\sigma_{n}\right\}, A\right) \leqq O\left(\left\{s_{n}\right\}, A\right)
$$

for every real sequence $\left\{s_{n}(x)\right\}$, defined over an infinite set $A$ and bounded above (below) over $A$ for all $n, \mathrm{C}_{4}, \mathrm{C}_{5}$, and $\mathrm{C}_{6}$ are necessary and sufficient.

The five theorems 7.21-7.233, the proofs of which are modifications of proofs of earlier theorems of this section, give necessary and sufficient conditions that $(T)$ shall transform sequences which converge uniformly over a set into sequences having the same property.

THEOREM 7.21. In order that $(T)$ may be such that $O\left(\left\{\sigma_{n}\right\}, A\right)=0$ for every sequence $\left\{s_{n}(x)\right\}$, defined over an arbitrary set $A$ and bounded over $A$. for all $n$, such that $O\left(\left\{s_{n}\right\}, A\right)=0$, no further conditions need be imposed on $a_{n k}$.

THEOREM 7.22. In order that $(T)$ may be such that $O\left(\left\{\sigma_{n}\right\}, A\right)=0$ for every sequence $\left\{s_{n}(x)\right\}$, defined over a finite set $A$, such that $O\left(\left\{s_{n}\right\}, A\right)=0$, no further conditions need be imposed on $a_{n k}$.

THEOREM 7.231. In order that $(T)$ may be such that $O\left(\left\{\sigma_{n}\right\}, A\right)=0$ for every sequence $\left\{s_{n}(x)\right\}$, defined over an infinite set $A$, such that $O\left(\left\{s_{n}\right\}, A\right)=0$, $\mathrm{C}_{5}$ and $\mathrm{C}_{6}$ are necessary and sufficient.

TheOREM 7.232. In order that a real $(T)$ may be such that $O\left(\left\{\sigma_{n}\right\}, A\right)=0$ for every real sequence $\left\{s_{n}(x)\right\}$, defined over an infinite set $A$, such that $O\left(\left\{s_{n}\right\}, A\right)=0, \mathrm{C}_{5}$ and $\mathrm{C}_{6}$ are necessary and sufficient.

THEOREM 7.233. In order that a real $(T)$ may be such that $O\left(\left\{\sigma_{n}\right\}, A\right)=0$ for every real sequence $\left\{s_{n}(x)\right\}$, defined over an infinite set $A$ and bounded above (below) over $A$ for all $n$, such that $O\left(\left\{s_{n}\right\}, A\right)=0, \mathrm{C}_{5}$ and $\mathrm{C}_{6}$ are necessary and sufficient. 


\section{UNIFORM OSCILLATON AND CONVERGENCE AT A POINT}

Let $\left\{f_{n}(x)\right\}$ be defined over a set $A$ and let $x_{0}$ be a point of $A^{0}$. Then the uniform oscillation of $\left\{f_{n}(x)\right\}$ at $x_{0}$ over $A$ (or measure of the deviation from uniform convergence of $\left\{f_{n}(x)\right\}$ at $x_{0}$ over $\left.A\right)$ is denoted by $O\left(x_{0} ;\left\{f_{n}\right\}, A\right)$ and is defined as follows: For each sequence $\left\{x_{i}\right\}$ of points of $A$ with the limit $x_{0}$, form

$$
\limsup _{m \rightarrow \infty, n \rightarrow \infty, i \rightarrow \infty}\left|f_{m}\left(x_{i}\right)-f_{n}\left(x_{i}\right)\right|=v ;
$$

the least upper bound of all such $v$ is $O\left(x_{0} ;\left\{f_{n}\right\}, A\right)$. A sequence $\left\{f_{n}(x)\right\}$ is said to converge uniformly at $x_{0}$ over $A$ when $O\left(x_{0} ;\left\{f_{n}\right\}, A\right)=0$. The proofs of the theorems of this section are similar to the proofs of the corresponding theorems of $\$ 5$, the essential difference occurring where the proofs of $\$ 5$ refer to $\$ 4$; in such cases the proofs of this section refer to $\$ 7$.

The eight theorems $8.111-8.133$ give necessary and sufficient conditions that $(T)$ shall not increase uniform oscillations of sequences at a point.

THEOREM 8.111. In order that $(T)$ may be such that

$$
O\left(x_{0} ;\left\{\sigma_{n}\right\}, A\right) \leqq O\left(x_{0} ;\left\{s_{n}\right\}, A\right)
$$

for every sequence $\left\{s_{n}(x)\right\}$, defined over a set $A$ such that $x_{0}$ is in $A^{0}$ and bounded over a neighborhood $D$ of $x_{0}$ in $A$ for all $n, \mathrm{C}_{4}$ is necessary and sufficient.

THEOREM 8.112. In order that a real $(T)$ may be such that

$$
O\left(x_{0} ;\left\{\sigma_{n}\right\}, A\right) \leqq O\left(x_{0} ;\left\{s_{n}\right\}, A\right)
$$

for every real sequence $\left\{s_{n}(x)\right\}$, defined over a set $A$ such that $x_{0}$ is in $A^{0}$ and bounded over a neighborhood $D$ of $x_{0}$ in $A$ for all $n, C_{4}$ is necessary and sufficient.

TheOREM 8.121. In order that $(T)$ may be such that

$$
O\left(x_{0} ;\left\{\sigma_{n}\right\}, A\right) \leqq O\left(x_{0} ;\left\{s_{n}\right\}, A\right)
$$

for every sequence $\left\{s_{n}(x)\right\}$, defined over a set $A$ of which $x_{0}$ is an isolated point, $\mathrm{C}_{4}$ is necessary and sufficient.

THEOREM 8.122. In order that a real $(T)$ may be such that

$$
O\left(x_{0} ;\left\{\sigma_{n}\right\}, A\right) \leqq O\left(x_{0} ;\left\{s_{n}\right\}, A\right)
$$

for every real sequence $\left\{s_{n}(x)\right\}$, defined over a set $A$ of which $x_{0}$ is an isolated point, $\mathrm{C}_{4}$ is necessary and sufficient. 
THEOREM 8.123. In order that a real $(T)$ may be such that

$$
O\left(x_{0} ;\left\{\sigma_{n}\right\}, A\right) \leqq O\left(x_{0} ;\left\{s_{n}\right\}, A\right)
$$

for every real sequence $\left\{s_{n}(x)\right\}$, defined over a set $A$ of which $x_{0}$ is an isolated point and bounded above (below) over a neighborhood $D$ of $x_{0}$ in $A$ for all $n$, $\mathrm{C}_{4}$ is necessary and sufficient.

ThEOREM 8.131. In order that $(T)$ may be such that

$$
O\left(x_{0} ;\left\{\sigma_{n}\right\}, A\right) \leqq O\left(x_{0} ;\left\{s_{n}\right\}, A\right)
$$

for every sequence $\left\{s_{n}(x)\right\}$, defined over a set $A$ of which $x_{0}$ is a limit point, $\mathrm{C}_{4}, \mathrm{C}_{6}$, and $\mathrm{C}_{6}$ are necessary and sufficient.

THEOREM 8.132. In order that a real $(T)$ may be such that

$$
O\left(x_{0} ;\left\{\sigma_{n}\right\}, A\right) \leqq O\left(x_{0} ;\left\{s_{n}\right\}, A\right)
$$

for every real sequence $\left\{s_{n}(x)\right\}$, defined over a set $A$ of which $x_{0}$ is a limit point, $\mathrm{C}_{4}, \mathrm{C}_{5}$, and $\mathrm{C}_{6}$ are necessary and sufficient.

TheOReM 8.133. In order that a real $(T)$ may be such that

$$
O\left(x_{0} ;\left\{\sigma_{n}\right\}, A\right) \leqq O\left(x_{0} ;\left\{s_{n}\right\}, A\right)
$$

for every real sequence $\left\{s_{n}(x)\right\}$, defined over a set $A$ of which $x_{0}$ is a limit point and bounded above (below) over a neighborhood $D$ of $x_{0}$ in $A$ for all $n, \mathrm{C}_{4}, \mathrm{C}_{5}$, and $\mathrm{C}_{6}$ are necessary and sufficient.

The five theorems 8.21-8.233 give necessary and sufficient conditions that $(T)$ shall transform sequences which converge uniformly at a point into sequences having the same property.

Theorem 8.21. In order that $(T)$ may be such that $O\left(x_{0} ;\left\{\sigma_{n}\right\}, A\right)=0$ for every sequence $\left\{s_{n}(x)\right\}$, defined over a set $A$ such that $x_{0}$ is in $A^{0}$ and bounded over a neighborhood $D$ of $x_{0}$ in $A$ for all $n$, such that $O\left(x_{0} ;\left\{s_{n}\right\}, A\right)=0$, no further conditions need be imposed upon $a_{n k}$.

THEOREM 8.22. In order that $(T)$ may be such that $O\left(x_{0} ;\left\{\sigma_{n}\right\}, A\right)=0$ for every sequence $\left\{s_{n}(x)\right\}$, defined over a set $A$ of which $x_{0}$ is an isolated point, such that $O\left(x_{0} ;\left\{s_{n}\right\}, A\right)=0$, no further conditions need be imposed upon $a_{n k}$.

Theorem 8.231. In order that $(T)$ may be such that $O\left(x_{0} ;\left\{\sigma_{n}\right\}, A\right)=0$ for every sequence $\left\{s_{n}(x)\right\}$, defined over a set $A$ of which $x_{0}$ is a limit point, such that $O\left(x_{0} ;\left\{s_{n}\right\}, A\right)=0, \mathrm{C}_{5}$ and $\mathrm{C}_{6}$ are necessary and sufficient. 
THEOREM 8.232. In order that a real $(T)$ may be such that $O\left(x_{0} ;\left\{\sigma_{n}\right\}, A\right)=0$ for every real sequence $\left\{s_{n}(x)\right\}$, defined over a set $A$ of which $x_{0}$ is a limit point, such that $O\left(x_{0} ;\left\{s_{n}\right\}, A\right)=0, \mathrm{C}_{5}$ and $\mathrm{C}_{6}$ are necessary and sufficient.

THEOREM 8.233. In order that a real $(T)$ may be such that $O\left(x_{0} ;\left\{\sigma_{n}\right\}, A\right)=0$ for every real sequence $\left\{s_{n}(x)\right\}$, defined over a set $A$ of which $x_{0}$ is a limit point and bounded above (below) over a neighborhood $D$ of $x_{0}$ in $A$ for all $n$, such that $O\left(x_{0} ;\left\{s_{n}\right\}, A\right)=0, \mathrm{C}_{5}$ and $\mathrm{C}_{6}$ are necessary and sufficient.

\section{UNIFORM OSCILLATION AND CONVERGENCE AT ALL POINTS AND LIMIT POINTS OF A SET}

In comparing the theorems of this section with those of $\S 7$, the following facts, given as lemmas, the proofs of which are similar to the proofs of the corresponding lemmas of $\S 6$, should be noted.

LEMMA 9.01. If $O\left(\left\{f_{n}\right\}, A\right) \leqq O\left(\left\{F_{n}\right\}, A\right)$ where $A$ contains more than one point, then it is not necessarily true that $O\left(x ;\left\{f_{n}\right\}, A\right) \leqq O\left(x ;\left\{F_{n}\right\}, A\right)$ over $A$.

LEMMA 9.02. If $O\left(\left\{f_{n}\right\}, A\right)=0, A$ being an arbitrary set, then $O\left(x ;\left\{f_{n}\right\}\right.$, $A)=0$ over $A^{0}$.

LEMMA 9.03. If $O\left(x ;\left\{f_{n}\right\}, A\right) \leqq O\left(x ;\left\{F_{n}\right\}, A\right)$ over $A^{0}$ and $A$ is compact, then $O\left(\left\{f_{n}\right\}, A\right) \leqq O\left(\left\{F_{n}\right\}, A\right)$.

Lemma 9.04. If $O\left(x ;\left\{f_{n}\right\}, A\right)=0$ over $A^{0}$ and $A$ is compact, then $O\left(\left\{f_{n}\right\}, A\right)=0$.

The theorems of this section are obtained from those of $\S 8$ as the theorems of $\S 6$ were obtained from those of $\S 5$. The eight theorems 9.111-9.133 give necessary and sufficient conditions that $(T)$ shall not increase the uniform oscillations of sequences at the points and limit points of a set.

THEOREM 9.111. In order that $(T)$ may be such that

$$
O\left(x ;\left\{\sigma_{n}\right\}, A\right) \leqq O\left(x ;\left\{s_{n}\right\}, A\right) \text { over } A^{0}
$$

for every sequence $\left\{s_{n}(x)\right\}$, defined over an arbitrary set $A$ and bounded over $A$ for all $n, C_{1}$ is necessary and sufficient.

THEOREM 9.112. In order that a real $(T)$ may be such that

$$
O\left(x ;\left\{\sigma_{n}\right\}, A\right) \leqq O\left(x ;\left\{s_{n}\right\}, A\right) \text { over } A^{0}
$$

for every real sequence $\left\{s_{n}(x)\right\}$, defined over an arbitrary set $A$ and bounded over $A$ for all $n, \mathrm{C}_{4}$ is necessary and sufficient. 
THEOREM 9.121. In order that $(T)$ may be such that

$$
O\left(x ;\left\{\sigma_{n}\right\}, A\right) \leqq O\left(x ;\left\{s_{n}\right\}, A\right) \text { over } A
$$

for every sequence $\left\{s_{n}(x)\right\}$, defined over a set $A$ without limit points, $C_{4}$ is necessary and sufficient.

THEOREM 9.122. In order that a real $(T)$ may be such that

$$
O\left(x ;\left\{\sigma_{n}\right\}, A\right) \leqq O\left(x ;\left\{s_{n}\right\}, A\right) \text { over } A
$$

for every real sequence $\left\{s_{n}(x)\right\}$, defined over a set $A$ without limit points, C. is necessary and sufficient.

THEOREM 9.123. In order that a real $(T)$ may be such that

$$
O\left(x ;\left\{\sigma_{n}\right\}, A\right) \leqq O\left(x ;\left\{s_{n}\right\}, A\right) \text { over } A
$$

for every real sequence $\left\{s_{n}(x)\right\}$, defined over a set $A$ without limit points and bounded above (below) over $A$ for all $n, \mathrm{C}_{4}$ is necessary and sufficient.

THEOREM 9.131. In order that $(T)$ may be such that

$$
O\left(x ;\left\{\sigma_{n}\right\}, A\right) \leqq O\left(x ;\left\{s_{n}\right\}, A\right) \text { over } A^{0}
$$

for every sequence $\left\{s_{n}(x)\right\}$, defined over a set $A$ with at least one limit point, $\mathrm{C}_{4}, \mathrm{C}_{5}$, and $\mathrm{C}_{6}$ are necessary and sufficient.

THEOREM 9.132. In order that a real $(T)$ may be such that

$$
O\left(x ;\left\{\sigma_{n}\right\}, A\right) \leqq O\left(x ;\left\{s_{n}\right\}, A\right) \text { over } A^{0}
$$

for every real sequence $\left\{s_{n}(x)\right\}$, defined over a set $A$ with at least one limit point, $\mathrm{C}_{4}, \mathrm{C}_{6}$, and $\mathrm{C}_{6}$ are necessary and sufficient.

THEOREM 9.133. In order that a real $(T)$ may be such that

$$
O\left(x ;\left\{\sigma_{n}\right\}, A\right) \leqq O\left(x ;\left\{s_{n}\right\}, A\right) \text { over } A^{0}
$$

for every real sequence $\left\{s_{n}(x)\right\}$, defined over a set $A$ with at least one limit point and bounded above (below) over $A$ for all $n, \mathrm{C}_{4}, \mathrm{C}_{5}$, and $\mathrm{C}_{6}$ are necessary and sufficient.

The five theorems 9.21-9.233 give necessary and sufficient conditions that $(T)$ shall transform sequences which converge uniformly at each point and limit point of a set into sequences having the same property. 
THEOREM 9.21. In order that $(T)$ may be such that $O\left(x ;\left\{\sigma_{n}\right\}, A\right)=0$ over $A^{0}$ for every sequence $\left\{s_{n}(x)\right\}$, defined over an arbitrary set $A$ and bounded in the neighborhood of each point of $A^{0}$ for all $n$, such that $O\left(x ;\left\{s_{n}\right\}, A\right)=0$ over $A^{0}$, no further conditions need be imposed upon $a_{n k}$.

Theorem 9.22. In order that $(T)$ may be such that $O\left(x ;\left\{\sigma_{n}\right\}, A\right)=0$ over $A$ for every sequence $\left\{s_{n}(x)\right\}$, defined over a set $A$ without limit points, such that $O\left(x ;\left\{s_{n}\right\}, A\right)=0$ over $A$, no further conditions need be imposed upon $a_{n k}$.

THEOREM 9.231. In order that $(T)$ may be such that $O\left(x ;\left\{\sigma_{n}\right\}, A\right)=0$ over $A^{0}$ for every sequence $\left\{s_{n}(x)\right\}$, defined over a set $A$ with at least one limit point, such that $O\left(x ;\left\{s_{n}\right\}, A\right)=0$ over $A^{0}, \mathrm{C}_{6}$ and $\mathrm{C}_{6}$ are necessary and sufficient.

THEOREM 9.232. In order that a real $(T)$ may be such that $O\left(x ;\left\{\sigma_{n}\right\}, A\right)=0$ over $A^{0}$ for every real sequence $\left\{s_{n}(x)\right\}$, defined over a set $A$ with at least one limit point, such that $O\left(x ;\left\{s_{n}\right\}, A\right)=0$ over $A^{0}, \mathrm{C}_{5}$ and $\mathrm{C}_{6}$ are necessary and sufficient.

THEOREM 9.233. In order that a real $(T)$ may be such that $O\left(x ;\left\{\sigma_{n}\right\}, A\right)=0$ over $A^{0}$ for every real sequence $\left\{s_{n}(x)\right\}$, defined over a set $A$ with at least one limit point and bounded above (below) over $A$ for all $n$, such that $O\left(x ;\left\{s_{n}\right\}, A\right)=0$ over $A^{0}, \mathrm{C}_{5}$ and $\mathrm{C}_{6}$ are necessary and sufficient.

Cornell University, ITHACA, N. Y. 